Number of tables: 0

Number of figures: 3

\title{
Probing for Neuroadaptations to Unpredictable Stressors in Addiction: Translational Methods and Emerging Evidence
}

\author{
Jesse T. Kaye MS, Daniel E. Bradford MS, Kate P. Magruder MS, \& John J. Curtin PhD \\ University of Wisconsin - Madison \\ 1202 West Johnson St., Madison, WI, 53706
}

Corresponding author:

John J. Curtin, PhD

1202 West Johnson St.

University of Wisconsin - Madison

Madison, WI 53706

Phone: 608-262-0387

Email: jjcurtin@wisc.edu

Preprint. This article may not exactly replicate the final version published in the journal. It is not the copy of record.

Final published citation: Kaye JT, Bradford DE, Magruder KP \& Curtin JJ (2017). Probing for neuroadaptations to unpredictable stressors in addiction: translational methods and emerging evidence. Journal of Studies on Alcohol and Drugs, 78, 353- 371. PMC5440361.

Funding: NIAAA (R01-AA024388; R01-AA15384; F31-AA022845), NIDA (R01-DA033809) 


\begin{abstract}
Stressors clearly contribute to addiction etiology and relapse in humans, but our understanding of specific mechanisms remains limited. Rodent models of addiction offer the power, flexibility, and precision necessary to delineate the causal role and specific mechanisms through which stressors influence alcohol and other drug use. This review describes a program of research using startle potentiation to unpredictable stressors that is well-positioned to translate between animal models and clinical research with humans on stress neuroadaptations in addiction. This research rests on a solid foundation provided by three separate pillars of evidence from 1) rodent behavioral neuroscience on stress neuroadaptations in addiction, 2) rodent affective neuroscience science on startle potentiation, and 3) human addiction and affective science with startle potentiation. Rodent stress neuroadaptation models implicate adaptations in corticotropinreleasing factor and norepinephrine circuits within the central extended amygdala following chronic alcohol and other drug use that mediate anxious behaviors and stress-induced reinstatement among drug-dependent rodents. Basic affective neuroscience indicates that these same neural mechanisms are involved in startle potentiation to unpredictable stressors in particular (vs predictable stressors). We believe that synthesis of these evidence bases should focus us on the role of unpredictable stressors in addiction etiology and relapse. Startle potentiation in unpredictable stressor tasks is proposed to provide an attractive and flexible testbed to encourage tight translation and reverse translation between animal models and human clinical research on stress neuroadaptations. Experimental medicine approaches focused on unpredictable stressors holds high promise to identify, repurpose, or refine pharmacological and psychosocial interventions for addiction.
\end{abstract}


We have long understood that stressors play a key role in alcohol and other drug use, and addiction $^{1}$. Stressors figure prominently in numerous seminal and contemporary theories on addiction etiology (Baker et al., 2004; Koob and Le Moal, 2008b; Sher, 1987; Solomon and Corbit, 1973). Most people report using drugs to cope with stressors at times, and report of stress-coping as a primary motivation for drug use predicts problematic use (Cooper et al., 1995; Kassel et al., 2003; Schroder and Perrine, 2007). Drug use disorders are highly comorbid with trauma and stressor-related disorders (Grant et al., 2016; McCarthy and Petrakis, 2010). Stressors or negative affect frequently precede relapse among drug dependent users pursuing abstinence (Brown et al., 1990; Shiffman and Waters, 2004). Similarly, stress-induced reinstatement of drug-seeking has been confirmed in rodent models (Mantsch et al., 2016).

Rodent models of addiction offer the power, flexibility, and precision necessary to delineate the causal role and specific mechanisms through which stressors influence drug use, addiction, and relapse (Koob, 2009; Koob and Le Moal, 2008a). Stressors clearly contribute to addiction etiology and relapse in humans as well, but our understanding of specific mechanisms remains much more limited than with rodents (Baker et al., 2004; Breese et al., 2011; Kassel et al., 2003). In this review, we propose a rodent-to-human translational framework to describe, evaluate, and offer novel predictions about the nature of these stress neuroadaptations in clinical research with humans. We begin with a brief overview of the processes and central nervous system (CNS) mechanisms that account for stress neuroadaptations in rodent models. Next, we advocate the use of a translational method from basic affective neuroscience using startle potentiation in unpredictable threat tasks to probe the phenotypic manifestation of these CNS stress neuroadaptations. Unpredictable stressors emerge from clinical research in humans to inform us about risk, etiologic mechanisms, and new treatments in addiction. We conclude by 
highlighting salient evidence gaps and unresolved questions along with promising future directions offered by this translational approach to study unpredictable stressors in addiction.

\section{Stress Neuroadaptations in Rodents: Opponent Process Mechanisms}

Over the past two decades, Koob and colleagues have proposed, evaluated, and iteratively refined a model of the processes and CNS mechanisms through which allostatic stress neuroadaptations cause addiction in rodent models (Koob and Le Moal, 2008a). This Stress Neuroadaptation model was initially derived from classic opponent process principles whereby countervailing brain stress systems (b-processes in opponent process theory) are recruited to oppose drug administration induced pleasure, positive affect, and reward-related activity (aprocesses) and restore affective neutrality (Koob and Le Moal, 2008b; Solomon and Corbit, 1973, 1974). Repeated recruitment of these brain stress systems to maintain affective homeostasis in the face of chronic drug use causes allostatic neuroadaptations that result in stronger and more persistent activation of these brain stress systems ${ }^{2}$. These neuroadaptations produce increased anxiety or other negative affect during drug deprivation after acute drug effects have ended but the strengthened b-process activation continues. Additional drug use is then motivated during deprivation via negative reinforcement that reduces this affectively aversive stress system activation.

These b-process stress neuroadaptations are proposed to involve changes in CRF and NE mechanisms within the central extended amygdala ${ }^{3}$. The extended amygdala is composed of the central $(\mathrm{CeA})$ and medial $(\mathrm{MeA})$ subnuclei of the amygdala, the bed nucleus of the stria terminalis (BNST), cell columns in the substantia innominata connecting the CeA and BNST, and a transition zone in the posterior portion of the medial nucleus accumbens bordering the BNST (Alheid and Heimer, 1988; Dong et al., 2001; Fox et al., 2015; Walker et al., 2003). The 
extended amygdala is further divided into the medial extended amygdala, which includes the MeA and medial subdivisions of the BNST, and the central extended amygdala, which includes the CeA and lateral subdivisions of the BNST (BNST ${ }_{\mathrm{L}}$ ). The CeA can be divided into several subdivisions, which most notably include the lateral and medial divisions $\left(\mathrm{Ce}_{\mathrm{L}}\right.$ and $\mathrm{CeA}_{\mathrm{M}}$, respectively). The $\mathrm{CeA}_{L}$ but not $\mathrm{Ce}_{\mathrm{M}}$ neurons contain large quantities of the neuropeptide $\mathrm{CRF}$ and these neurons are a major source of the CRF in the $\mathrm{BNST}_{\mathrm{L}}$ (Day et al., 1999; Gray and Magnuson, 1987; Sakanaka et al., 1986). This CRF signaling in the central extended amygdala combines with modulatory impacts of $\mathrm{NE}$ in the $\mathrm{BNST}_{\mathrm{L}}$ to mediate behavioral responses to environmental and internal stressors.

Stress neuroadaptations in these CRF and NE sensitive pathways in the central extended amygdala appear to be involved in the motivational states associated with drug deprivation and stress-induced reinstatement of drug seeking in rodents (Aston-Jones and Harris, 2004; Erb, 2010; Koob, 2009, 2010; Mantsch et al., 2016; Silberman and Winder, 2013; Smith and AstonJones, 2008). To start, deprivation of many drugs (i.e., alcohol, nicotine, cocaine, opioids, cannabinoids) consistently increases CRF and NE levels in the central extended amygdala (for reviews see Koob, 2009; Silberman and Winder, 2013; Smith and Aston-Jones, 2008). Drug deprivation also elicits anxiety-like behaviors across a number of behavioral models (e.g., defensive burying, startle response, elevated plus maze, freezing; Baldwin et al., 1991; George et al., 2007; Harris and Aston-Jones, 1993; Jonkman et al., 2007; Olive et al., 2002). Direct injections of CRF or NE agonists, particularly into the extended amygdala, also increase anxietylike behavior at baseline and during drug deprivation (George et al., 2007; Liang et al., 1992; Park et al., 2013; Swerdlow et al., 1986). Critically, CRF and NE receptor antagonists, administered intracerebroventricular (i.c.v.) or directly in the extended amygdala, reduce these 
same anxiety-like behaviors during deprivation (George et al., 2007; Harris and Aston-Jones, 1993; Rudoy and Van Bockstaele, 2007; Skelton et al., 2007), supporting a causal role for these neurotransmitter systems in anxiety-like behaviors during deprivation.

Stress-induced reinstatement to drug-seeking is also mediated by similar CRF and NE mechanisms ${ }^{4}$ in rodents (for reviews see Mantsch et al., 2016; Shaham, Erb, et al., 2000). In this canonical model of drug relapse, unpredictable footshock reliably and robustly reinstates drugseeking behavior across nearly all classes of addictive drugs including nicotine (Buczek et al., 1999), alcohol (Lê et al., 1998), heroin (Shaham and Stewart, 1995), cocaine (Erb et al., 1996), and methamphetamine (Shepard et al., 2004). However, pharmacologic manipulations that increase CRF are also sufficient to reinstate drug-seeking to nicotine (Zislis et al., 2007), alcohol (Lê et al., 2000), heroin (Shaham et al., 1997), cocaine (Brown et al., 2009; Erb and Stewart, 1999), and methamphetamine (Nawata et al., 2012). Likewise, manipulations to increase NE reinstate drug-seeking to nicotine (Feltenstein et al., 2012), alcohol (Lê et al., 2005), heroin (Shaham, Highfield, et al., 2000), cocaine (Erb et al., 2000), and methamphetamine (Shepard et al., 2004) ${ }^{5}$. Moreover, CRF receptor antagonists potently reduce stress-induced reinstatement to nicotine (Bruijnzeel et al., 2009; Plaza-Zabala et al., 2010), alcohol (Gehlert et al., 2007; Lê et al., 2000), heroin (Shaham et al., 1997), cocaine (Erb et al., 2001; Shaham et al., 1998), and methamphetamine (Nawata et al., 2012). Comparable evidence suggests blocking NE neurotransmission reduces stress-induced reinstatement to nicotine (Zislis et al., 2007), alcohol (Funk et al., 2016; Lê et al., 2005, 2011), heroin (Shaham, Highfield, et al., 2000), and cocaine (Erb et al., 2000). Although much of the research on stress-induced reinstatement has used nonspecific central CRF/NE manipulations (e.g., i.c.v. injections), evidence suggests these effects 
are mediated in part by CeA to BNST pathways (Erb and Stewart, 1999; Shaham, Highfield, et al., 2000; for reviews see Silberman and Winder, 2013; Smith and Aston-Jones, 2008). Probing Stress Neuroadaptations in Humans: A Translational Focus on CNS Mechanisms Stressors activate CNS, hormonal, and peripheral biological systems that produce changes in affect, arousal, attention, energy mobilization, immune and inflammatory responses, and other processes to support adaptive responding to the challenge (Arnsten, 2009; McEwen and Gianaros, 2011; Sapolsky, 2002). A central thesis of the behavioral neuroscience research in rodents that we have reviewed is that "a key element of the addiction process involves a profound activation of stress systems in the brain that interacts but is independent of hormonal stress systems" (Koob, 2009, p. 62; see also Shaham et al., 1997). Nonetheless, over the last two decades the majority of addiction research examining the stress response in humans has focused on mechanisms involving the hypothalamic-pituitary-adrenal (HPA) axis (for reviews see al'Absi, 2006; Sinha, 2008). Stressors elicit CRF release from the hypothalamus, which triggers a hormonal cascade resulting in glucocorticoid (i.e., cortisol in humans) release from the adrenal gland. Given the clear role that glucocorticoids play in mediating the body's physiological response to stressors, clarifying the impact of acute and chronic drug use on HPA-axis function has important health implications (McEwen and Gianaros, 2011) ${ }^{6}$. However, we believe that an increased focus on CNS stress systems (e.g., extrahypothalamic CRF) and their behavioral and affective consequences is critical to translate findings from rodent models to human addiction.

Multiple approaches will be necessary to confirm the rodent stress neuroadaptation thesis in humans and to clarify its affective and behavioral consequences. Nonetheless, approaches that can bridge between neural, affective, and behavioral domains of analysis should be prioritized. Self-report approaches provide a unique window into the subjective emotional experience of 
drug dependent individuals (Baker et al., 2004; Piper, 2015; Witkiewitz, 2011). However, much of the motivational press to use drugs may operate outside of conscious awareness (Tiffany, 1990). Perhaps more importantly, self-report alone is too distal from the neural mechanisms implicated by rodent models to confirm these mechanisms in humans. Conversely, human neuroimaging approaches hold considerable promise to probe the neural mechanisms implicated by rodent models. However, these approaches alone will not be sufficient given their cost and technological barriers that currently limit their precision to parse putatively distinct circuits in the central extended amygdala in humans (Avery et al., 2016; Fox et al., 2015; but see Shackman and Fox, 2016).

Psychophysiological approaches that are firmly grounded in rodent-to-human translational tasks are attractively situated between neural circuits and behavior/self-report domains such that they can bridge between neurobiological and psychological referents (Patrick and Hajcak, 2016). We believe startle potentiation measured in cued threat tasks may represent a powerful and flexible, yet also cost-efficient and broadly accessible, method to translate research from rodent models on CNS stress neuroadaptation mechanisms to understand affect, behavior, and subjective experience in human drug users.

\section{Startle Potentiation during Unpredictable Threats}

Basic research in affective neuroscience has relied extensively on the measurement of the startle response in cued threat tasks to explicate psychological and neural mechanisms involved in response to these stressors in animals and humans (Davis, 2006; Davis et al., 2010; Grillon, 2008). The startle response to an abrupt, intense stimulus (e.g., loud noise) is potentiated above baseline when elicited during a salient threat or in an aversive context (Grillon et al., 1991; Grillon and Davis, 1997). The startle response can be elicited, potentiated, and measured using 
very similar methods among rodents, non-human primates, and humans (see Figure 1). As such, use of startle potentiation in cued threat tasks can provide an important animal-human translational bridge to study stress mechanisms in addiction across animal models and human clinical research (for reviews see Davis et al., 2008, 2010).

The startle response is potentiated across species by well-defined, precise, predictable threats such as the administration of cue-contingent electric shock (Grillon and Davis, 1997; Hitchcock and Davis, 1991). Startle potentiation is also observed during threats where the associated threat is less predictable. For example, unpredictable shock administration potentiates the startle response in both animals and humans (Campeau et al., 1991; Grillon et al., 2004; Grillon and Davis, 1997). Similarly, darkness in humans and bright light or predator-related stimuli (e.g. odor of fox feces) potentiate the startle response given the potential unpredictable dangers associated with these stimuli for humans and rodents, respectively (Endres et al., 2005; Grillon et al., 1997; Walker and Davis, 1997a). Substantial research suggests that predictable and unpredictable threats produce different subjective emotional states that are associated with distinct temporal patterns of startle potentiation. Furthermore, the neural mechanisms that mediate startle potentiation to predictable and unpredictable threats are also partially separable.

Startle potentiation to both predictable and unpredictable threats is mediated by the central extended amygdala, but through partially distinct circuitry and neurotransmitter systems. The $\mathrm{CeA}_{\mathrm{M}}$ and its projections to brainstem areas appear responsible for startle potentiation and related behaviors in rodents during imminent, cue-contingent electric shock and other predictable threats (Davis et al., 2010; Walker and Davis, 1997b, 2008). In contrast, substantial evidence suggests startle potentiation during unpredictable threats is dependent on NE and CRF sensitive pathways through the $\mathrm{CeA}_{\mathrm{L}}$ and the $\mathrm{BNST}_{\mathrm{L}}$ (Davis et al., 2010; Walker et al., 2009; Walker and 
Davis, 2002). As noted earlier, the $\mathrm{CeA}_{L}$ but not the $\mathrm{Ce} \mathrm{A}_{M}$ has a large number of CRF-positive neurons and these neurons appear to be a major source of CRF for the BNST $\mathrm{L}_{\mathrm{L}}$ (Sakanaka et al., 1986). CRF infusions directly into the $\mathrm{BNST}_{\mathrm{L}}$ enhance startle potentiation (Lee and Davis, 1997) and excitotoxic $\mathrm{BNST}_{\mathrm{L}}$ lesions, or local infusions of a CRF antagonist into the $\mathrm{BNST}_{\mathrm{L}}$ completely block CRF-enhanced startle potentiation (Lee and Davis, 1997; Liang et al., 1992; Walker et al., 2009). The $\mathrm{BNST}_{\mathrm{L}}$ is involved in sustained startle potentiation by temporally unpredictable shock during long/variable duration (up to 8 minutes) shock threat cues but not phasic startle potentiation by imminent, temporally predictable shock during brief (3.7 seconds) shock threat cues (Walker and Davis, 2008). Moreover, a CRF antagonist dose-dependently blocks startle potentiation to unpredictable long duration, but not predictable short duration CSs (Walker et al., 2009). Similarly, drugs that reduce NE activation also reduce startle potentiation due to unpredictable shock or CRF administration (Gresack and Risbrough, 2011; Manion et al., 2007) and systemic administration of a CRF antagonist blocks light-enhanced startle potentiation, another unpredictable threat in rodents (de Jongh et al., 2003; Walker et al., 2009). Synthesis of this evidence strongly implicates selective involvement of CRF/NE sensitive circuits in the central extended amygdala in response to unpredictable threats in rodents. As such, startle potentiation to unpredictable threats emerges as an attractive measure to probe for stress neuroadaptations in these neural mechanisms in human addiction.

\section{The NPU and Related Unpredictable Threat Tasks}

Grillon and colleagues have developed a widely used laboratory stress task in humans, the No-Shock, Predictable Shock, Unpredictable Shock (NPU) task (Grillon et al., 2004; Schmitz and Grillon, 2012). The NPU task represents a careful translation of procedures with rodents involving temporally predictable and unpredictable electric shock (e.g., see Walker and Davis, 
2008) that they adapted for use in humans (see Figure 2). Kaye, Bradford, \& Curtin (2016) recently evaluated the psychometric properties of startle potentiation in the NPU task and concluded it possesses good internal consistency and temporal stability both within individuals and groups (also see Nelson et al., 2015; Shankman et al., 2013). The NPU task is attractive because it can easily accommodate parametric manipulations of numerous task factors (e.g., cue duration, cue-shock contingencies, shock intensity) to support programmatic research and conceptual replication efforts. The NPU and these related tasks can also accommodate additional dependent measures (e.g., self-report, event related potentials, facial electromyography, fMRI) to provide more comprehensive assessment of the subjective, cognitive, physiological, and neural response to predictable and unpredictable threats (Alvarez et al., 2011; Bradford et al., 2013; Kaye et al., 2016; Nelson et al., 2015).

Medications with expected anxiolytic or anxiogenic effects have been administered in healthy controls to evaluate if the NPU task is sensitive to the putative impact of these drugs on physiological stress mechanisms broadly. As expected, acute administration of benzodiazepines selectively reduces startle potentiation to unpredictable but not predictable threat (Baas et al., 2002; Grillon et al., 2006). The effect of SSRIs on unpredictable threat startle potentiation mirrors their clinical profile. Specifically, acute administration of SSRIs is anxiogenic and increases startle potentiation to unpredictable threat (Grillon, Levenson, et al., 2007) whereas chronic administration is anxiolytic and decreases startle potentiation to unpredictable threat (Grillon et al., 2009). Similarly, tryptophan depletion, which grossly reduces serotonin levels, selectively increases startle potentiation to unpredictable threat (Robinson et al., 2012).

Limited available evidence suggests that startle potentiation during unpredictable and predictable threats in the NPU are likely mediated by similar neural circuits in humans as 
rodents. In a version of the NPU task implemented via virtual reality, Alvarez et al (2011) observed transient increased fMRI activity in the dorsal amygdala during both predictable and unpredictable shock. The dorsal amygdala includes the CeA, among other subnuclei in humans. As such, this is consistent with the involvement of the $\mathrm{Ce}_{M}$ and $\mathrm{Ce}_{L}$ in rodents predictable and unpredictable threats, respectively, although fMRI in humans does not have adequate spatial resolution to parse divisions of the CeA. Equally important, unpredictable but not predictable shock produced sustained fMRI activity in a basal forebrain region that encompasses the BNST complex (also see Somerville et al., 2010), which is also consistent with the selective involvement of the $\mathrm{BNST}_{\mathrm{L}}$ during unpredictable threats in rodents.

Direct and indirect pharmacological manipulations of the extrahypothalamic CRF system on startle potentiation in the NPU task have also been evaluated. Acute hydrocortisone administration, which may indirectly increase extrahypothalamic CRF (see footnote 6; Schulkin et al., 2005), selectively increases startle potentiation to unpredictable threat (Grillon et al., 2011). However administration of the selective CRF-1 antagonist, GSK561679 (verucerfont), did not decrease startle potentiation to unpredictable threat as would be expected (Grillon et al., 2015). Instead this CRF-1 antagonist increased startle potentiation during predictable threat, which the authors speculate may be due to blocking inhibitory projections from BNST to mCeA that mediate fear-potentiated startle (Walker et al., 2009).

\section{Human Startle Potentiation during Unpredictable Stressors in Addiction}

Addiction research using drug administration is useful to document the reinforcing properties of drugs that encourage their use. Equally important, these studies may also identify drug effects that recruit homeostatic regulatory processes following each administration and promote compensatory neuroadaptations following chronic use. Drug deprivation studies can 
confirm phenotypes consistent with these predicted neuroadaptations among drug dependent users. Studies of protracted abstinence can probe the time course and persistence of these neuroadaptations. Consistent use of the same translational tasks across rodents and humans and across drug administration, deprivation, and protracted abstinence studies allows for clearer synthesis of findings. We believe that startle potentiation during unpredictable threat tasks is well suited to meet this goal. As such, there has been increasing interest in these translational tasks to probe the impact of acute and chronic drug use on affective response to stressors.

\section{Alcohol Administration Studies}

Curtin and colleagues have examined the acute effects of a single administration of alcohol on response to unpredictable vs. predictable shock threat among recreational drinkers ${ }^{7}$. Moberg \& Curtin (2009) demonstrated that a moderate dose of alcohol (blood alcohol concentration; $\mathrm{BAC}=0.08 \%$ ) selectively reduced startle potentiation during unpredictable but not predictable shock threat in the NPU task. Following this, Curtin and colleagues demonstrated that this selective stress response dampening effect during unpredictable (vs. predictable) threat was robust by programmatically examining diverse manipulations of threat unpredictability. Across four additional studies, alcohol administration produced significantly greater reductions in startle potentiation during unpredictable vs. predictable shock threat regardless of whether unpredictability was established via manipulation of the timing (Hefner et al., 2013), probability (Hefner and Curtin, 2012), intensity (Bradford et al., 2013), or location (Bradford et al., in prep) of the shock threat (see Figure 3). This selective effect of alcohol on unpredictable vs. predictable threat was consistent when contrasted with either placebo (Hefner et al., 2013; Hefner and Curtin, 2012; Moberg and Curtin, 2009) or true no-alcohol control groups (Hefner et 
al., 2013). This selective alcohol effect also appears to be dose dependent, increasing linearly across a broad range of BACs up to $0.16 \%$ (Bradford et al., in prep, 2013).

These recent demonstrations that alcohol only provides stress response dampening during unpredictable but not predictable threats may help resolve the long history of what previously appeared to be inconsistent effects across studies (Curtin and Lang, 2007; Sher, 1987). The unpredictability lens may also provide a comparable mechanism for patterns of alcohol stress response dampening proposed by influential cognitive theories. Steele and Josephs (1990) proposed that alcohol reduces the stress response only when drinkers are distracted. Sayette (1993) has carefully documented that alcohol stress response dampening occurs in the laboratory when threats are not adequately appraised. It may be that distraction and appraisal deficits serve to make stressors less predictable and therefore more susceptible to alcohol's influence.

\section{Drug Deprivation and Abstinence Studies}

Although all drinkers may experience alcohol stress response dampening to some degree, alcoholics may experience exceptionally strong affective negative reinforcement due to stress neuroadaptations following chronic alcohol use. Moberg et al., (2016) recently demonstrated that alcohol dependent participants in early abstinence (1-8 weeks) displayed increased startle potentiation to unpredictable (vs. predictable) shock threat relative to healthy controls. These observations are consistent with earlier evidence in the NPU task that participants with comorbid panic disorder and alcohol dependence displayed increased startle potentiation during unpredictable shock threat relative to both participants with only panic disorder and healthy controls (Gorka et al., 2013). No differences in startle potentiation during predictable shock threat were observed among these three groups. Gorka and colleagues concluded that increased reactivity to unpredictable threat represented an important process to explain the comorbidity 
between these two disorders. However, it may be that alcohol dependence alone is sufficient to produce selective increase in startle potentiation to unpredictable threat.

Stress neuroadaptations are proposed to emerge to oppose positive affect and reward related activity produced by addictive drugs other than alcohol. Hogle et al., (2010) provided evidence of stress neuroadaptation in smokers in a between-subjects version of the NPU task. Nicotine deprived (24 hours) and non-deprived smokers displayed comparable startle potentiation during predictable shock threat. However, startle response during unpredictable shock threat was increased among nicotine-deprived smokers. Similarly, Grillon et al., confirmed increased startle potentiation during unpredictable air blast blocks but not predictable air blast cues in overnight deprived smokers relative to non-smokers (Grillon, Avenevoli, et al., 2007). Unexpectedly, deprived and non-deprived smokers did not differ with respect to unpredictable startle potentiation, but task sensitivity may have been reduced by use of a less potent threat (air blast vs. electric shock) and/or weak manipulation of deprivation (overnight vs. 24 hours). Other evidence suggests that chronic marijuana and opiate use in humans may also selectively impact the mechanisms that mediate response to unpredictable threats. For example, preliminary analyses indicate that heavy daily marijuana smokers display increased response to unpredictable shock threat (Hefner et al., in prep). Yohimbine has also been used to potentiate the startle response via NE mechanisms in rodents and humans (Kehne and Davis, 1985; Morgan et al., 1993; but see footnote 5). Stine et al., (2001) demonstrated that yohimbine-potentiated startle was greater among opiate dependent patients than healthy controls. Yohimbine also increased withdrawal symptoms, self-reported anxiety, and levels of an NE metabolite in these same participants (Stine et al., 2002). In contrast, opiate dependent patients did not display increased baseline startle reactivity relative to healthy controls. Available evidence suggests the baseline 
startle reactivity is also not increased during acute nicotine deprivation, acute marijuana deprivation or in early alcohol abstinence when no unpredictable threat is involved (Grillon, Avenevoli, et al., 2007; Hefner et al., in prep; Hogle et al., 2010; Hogle and Curtin, 2006; Moberg et al., 2016; Mueller et al., 1998).

\section{Experimental Therapeutics for Addiction: Stress Mechanisms to Treatment}

The NIMH has recently advanced a potentially powerful initiative which they refer to as the Experimental Therapeutics Paradigm (Insel, 2015; Insel and Gogtay, 2014). This initiative refocuses clinical trials to evaluate not only intervention efficacy but also mechanism. As such, the experimental therapeutics paradigm requires that clinical trials explicitly measure pertinent mechanism(s) of either the disease process or the action of the intervention. In particular, the use of "surrogate endpoints" - early markers of disease process mechanisms with high predictive validity for later clinical outcomes - offer high promise to increase the pace of clinical trials research to develop and refine medications and other interventions within this new paradigm (Insel, 2012; Lerman et al., 2007; Litten et al., 2016; McKee, 2009).

We believe that promising surrogate endpoints to evaluate unpredictable stressor mechanisms in addiction are now available in three laboratory tasks. This review paper clearly highlights startle potentiation in the NPU task to measure physiological response to unpredictable and predictable threats (Schmitz and Grillon, 2012). Self-reported anxiety and craving, and cortisol response in either the stress and drug cue imagery task (Sinha, 2009) or a combined Trier Social Stress and cue reactivity task (Kwako, Schwandt, et al., 2015) have also been used to measure subjective and physiological stress response. Importantly, these surrogate endpoint measures are all sensitive to the respective stressors in their associated laboratory tasks. Only the NPU task explicitly contrasts response to unpredictable (vs. predictable) stressors, 
which may provide increased selectivity to detect stress neuroadaptations in CRF and NE sensitive pathways in the central extended amygdala. However, it may be that the stressors in these other two imagery and Trier tasks are best considered unpredictable as well (e.g., description of an unexpected relationship breakup in the imagery task, uncertain social evaluation by strangers during public speaking in the Trier task) so this distinction between tasks may not prove critical. Startle potentiation in the NPU task may also be relatively attractive for its tighter translation of both measure and methods from preclinical research with rodents.

For optimal use in the experimental therapeutics paradigm, these surrogate endpoints must also be robust predictors of clinically relevant outcomes in addiction (e.g., time to lapse, relapse probability). Unfortunately, the predictive validity of startle potentiation in the NPU task has not been evaluated to date, although efforts are underway (NIAAA $\underline{\text { R01-AA024388 }}$ and

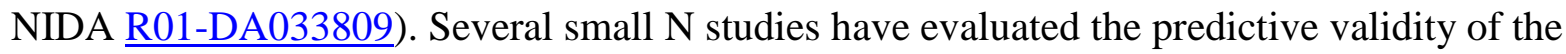
surrogate endpoints in the imagery and Trier social stress tasks (Back et al., 2010; Sinha et al., 2006; Sinha, Fox, et al., 2011). However, convincing evidence has not yet accumulated for any of these endpoint/task combinations given the inconsistent pattern of associations observed across studies, specific surrogate endpoint measures, and clinical outcome measures. We believe that concerted efforts must be directed to evaluating these surrogate endpoints in all three tasks in large, well-powered studies for this experimental therapeutics paradigm to advance development of interventions for stress-induced relapse in addiction.

A handful of laboratories have already initiated and/or completed clinical trials using these surrogate endpoints to evaluate medications targeting involvement of NE or CRF neurotransmitter systems in the stress response in addiction (for review, see Mantsch et al., 2016). Although such efforts may at first appear premature, this research should be considered an 
iterative attempt to simultaneously bootstrap evidence regarding the predictive validity and/or neurotransmitter mechanisms of the surrogate endpoints in these laboratory tasks, while also providing preliminary evidence of the clinical efficacy of these medications that are strongly motivated from preclinical rodent models (Koob et al., 2009).

Several FDA-approved medications for other clinical indications have generated some preliminary excitement for their potential to target NE stress mechanisms for relapse prevention in addiction. A few small studies demonstrated that alpha2 agonists reduced subjective measures of stress-induced craving in the imagery task with patients with opioid (i.e., lofexidine, Sinha et al., 2007), cocaine (i.e., clonidine, Jobes et al., 2011), and nicotine (i.e., guanfacine, McKee et al., 2015) addiction. Similarly another preliminary study using the imagery task found promising results of alpha1 antagonist reducing stress-induced craving in alcoholics (i.e., prazosin, Fox, Anderson, et al., 2012). However, the predicted effects have not been consistent for all subjective (e.g., craving, anxiety) or physiological (e.g., cortisol, blood pressure) measures or task conditions (e.g., stress- vs drug cue-induced imagery) across all studies (Fox et al., 2014; Fox, Seo, et al., 2012; Moran-Santa Maria et al., 2015). Clearly these studies warrant cautious interpretation given small sample sizes, lack of robust converging evidence across tasks/measures, and previously acknowledged weak evidence of the predictive validity of these surrogate endpoints. Likewise, several Phase 2 randomized clinical trials examining the efficacy of alpha1 antagonists on clinical outcomes for alcoholism have yielded some positive (Simpson et al., 2009, 2015), equivocal (Kenna et al., 2015), and negative (Petrakis et al., 2016) results, leaving the question of their clinical utility unanswered to date. As one next step, our laboratory is currently examining the effect of an alpha1 antagonist, doxazosin, simultaneously on the NPU 
startle potentiation surrogate endpoint and short term (8 weeks) clinical outcomes in a large sample of patients with alcohol use disorder (NIAAA $\underline{\text { R01-AA024388). }}$.

In contrast to the more promising results from medications that target the NE system, two recent studies have failed to detect the predicted effects of CRF-1 antagonists on stress mechanisms in alcoholics (Kwako, Spagnolo, et al., 2015; Schwandt et al., 2016). Both studies were rigorous implementations of the experimental therapeutics paradigm with surrogate endpoints. Specifically, both studies used multiple endpoints to assess subjective (self-reported distress and craving) and physiological (cortisol) stress response in both the imagery and Trier tasks. Both selected a more homogenous sample of alcoholics by recruiting only patients with elevated trait anxiety scores. Two different CRF-1 antagonists (pexacerfont, verucerfont) with different pharmacokinetics were used across two studies. Conversely, it must be acknowledged that both were likely under-powered given their small sample sizes $(\mathrm{N}=39-54$, drug vs placebo between-subjects), which unfortunately remains too common for research using surrogate endpoints (Button et al., 2013; Ioannidis, 2005). Moreover, they evaluated only surrogate endpoints, but not any clinical outcomes. As the authors acknowledge, it could be argued that absent robust evidence of predictive validity, null findings for surrogate endpoints are difficult to interpret unambiguously. We hope that null findings from these two studies are not sufficient to terminate further development and evaluation of medications that target CRF mechanisms given the exceptionally strong preclinical evidence that has accumulated from rodent models across many labs in the past two decades. Nonetheless, we are not naïve about the pressures that weigh against further exploration including growing concern about translation of preclinical findings to humans (Insel, 2012; Kapur et al., 2012; Miller, 2010), the previous failures of CRF-1 antagonists in phase 3 trials with clinical outcomes for mood and anxiety disorders (Binneman et 
al., 2008; Coric et al., 2010; but see Koob and Zorrilla, 2012), and practical issues regarding medication availability and public/private funding of future research (see Shaham and de Wit, 2016, for additional commentary).

\section{Integrative Discussion and Future Directions}

\section{Novel Insights about the Stress Neuroadaptation Model}

This review synthesized three separate pillars of evidence from 1) rodent behavioral neuroscience on stress neuroadaptations in addiction, 2) rodent affective neuroscience science on startle potentiation, and 3) human addiction and affective science with startle potentiation. The rodent Stress Neuroadaptation Model indicates that drug-induced adaptations in CRF and NE circuits within the central extended amygdala mediate anxious behaviors and stress-induced reinstatement. Rodent affective neuroscience clarifies that these mechanisms support "dynamic, active response to an acute stressor" rather than tonic, persistent negative mood states (Koob and Zorrilla, 2012, p. 309; also see Heilig et al., 2011). Rodent affective science with startle potentiation indicates that these same neural mechanisms are recruited selectively to respond to unpredictable (vs. predictable) stressors. Translational methods measuring startle potentiation during unpredictable vs. predictable stressors in humans clarify that drug administration and deprivation effects are observed selectively during unpredictable stressors as well. We conclude that future research on the etiology of addiction and causes of relapse guided by the stress neuroadaptation model should be focused on unpredictable stressors.

Our focus on unpredictable stressors also raises questions about the necessary eliciting conditions for negative affect and its conceptualization as a symptom of the withdrawal syndrome. Baker's seminal negative reinforcement model of addiction indicates that negative affect emerges directly from falling drug levels that initiate the drug withdrawal syndrome 
(Baker et al., 2004). Similarly, opponent process principles underlying the Stress

Neuroadaptation Model suggest that drug administration automatically recruits opposing bprocess brain stress circuits that result in the anxiety-like behavior that manifests as a withdrawal syndrome shortly after deprivation onset. However, the relevant circuits implicated by the Stress Neuroadaptation Model mediate dynamic, active response to an acute stressor rather than longer lasting changes in negative affect that emerge and persist without instigation simply from drug deprivation. Furthermore, drug deprivation or abstinence alone do not appear to be sufficient to potentiate the startle response in humans. Instead, startle potentiation differences between deprived/abstinent participants and controls have only been observed when unpredictable threats are introduced. These observations cast some doubt on whether drug deprivation alone is a sufficient cause to activate these stress circuits and their affective consequences.

Instead, it may be that unpredictable stressors, but not drug deprivation per se, are necessary (and perhaps sufficient) causes of the activity in these stress circuits, the observed increase in anxiety and other negative affect we associate with withdrawal following deprivation, and the associated increase in relapse risk. For example, most behavioral neuroscience models that probe brain stress circuits and associated anxiety-like behavior in rodents during deprivation involve a stressor as part of the assay itself (e.g., footshock instigates defensive burying), suggesting that the behavioral observations may reflect stressor-reactivity rather than a consequence of deprivation itself (Smith and Aston-Jones, 2008, pp. 47-48). Similarly, unpredictable footshock reinstates drug use well beyond the periods of frank drug withdrawal during acute deprivation (Mantsch et al., 2016). It seems parsimonious to speculate that unpredictable stressors elicit phasic negative affect and motivate drug use via comparable stress 
neuroadaptation mechanisms regardless of deprivation state in the non-abstinent drug user, during withdrawal following acute deprivation, and into protracted abstinence.

If exaggerated reactivity to unpredictable stressors resulting from stress neuroadaptations is the cause of the negative affect typically associated with the withdrawal syndrome, why does it appear to emerge shortly after the onset of drug deprivation? In humans, the initial abstinence period itself is characterized by substantial unpredictability in the onset, magnitude, and other temporal characteristics of aversive withdrawal symptoms (Heilig et al., 2010). These physical withdrawal symptoms may serve as unpredictable stressors. Furthermore, even the treatmentmotivated drug user may still be uncertain if their nascent cessation efforts will be successful, adding further unpredictable stress at the start of their quit attempt. These endogenous stressors may combine with frequent exogenous unpredictable stressors common during early recovery. This may create the appearance of tonic, persistent negative affect emerging as part of the withdrawal syndrome following drug deprivation when the true causes are frequent unpredictable stressors and affective changes are tightly coupled to these stressors.

Future human clinical research should more carefully measure and control endogenous and exogenous stressors when examining negative affect as part of the withdrawal syndrome. Advances in methodology to support more precise, repeated real time measurements of affective response already provide some evidence to challenge the notion of stable negative affect narrowly observed during short-lived periods of acute deprivation (Piasecki et al., 1998, 2000). High intra-individual variability in self-reported negative affect in the days and weeks following cessation of drug use is common (Piper et al., 2011), and this may be in part driven by unpredictable stressors that remain difficult to measure in real-world settings. These observations 
should also stimulate reverse translation to contrast findings across behavioral neuroscience models that do and do not incorporate explicit stressors as part of the measurement procedure.

We believe our review also highlights a novel counteradaptational process that has yet to be formally specified or studied as part of the Stress Neuroadaptation model. Koob has suggested two broad classes of allostatic counteradaptational processes contribute to addiction etiology: between-systems neuroadaptations and within-system neuroadaptations (Koob and Bloom, 1988; Koob and Le Moal, 2008b). Between-systems neuroadaptations follow directly from opponent process model principles, where a- and b-processes emerge from activation of distinct motivational systems in the brain. For example, stress neuroadaptations appear to result, in part, from a between-system neuroadaptation where brain stress system circuits are repeatedly recruited and strengthened to offset acute drug effects within the reward system (Koob and Le Moal, 2008b; Solomon and Corbit, 1973). In rodents, this mechanism is proposed to operate broadly given that most addictive drugs robustly recruit reward system activation.

In contrast, within-system neuroadaptations occur when the primary cellular response within a specific system adapts to neutralize the drug's effects within that same system (Koob and Le Moal, 2008b). Koob and others have focused extensively on within-system adaptations that occur in the reward system itself to maintain homeostasis in the face of repeated reward system recruitment by chronic administration of drug in rodents. We believe that the human unpredictable startle potentiation studies reviewed here suggest the possibility of within-system neuroadaptations in the stress system as well, at least for alcohol. Specifically, we provided robust evidence that acute administration of alcohol selectively reduces startle potentiation to unpredictable stressors in humans (Bradford et al., 2013; Hefner et al., 2013; Hefner and Curtin, 2012; Moberg and Curtin, 2009). It seems plausible that chronic suppression of reactivity to 
unpredictable stressors from repeated alcohol administration (or other drugs that produce stress response dampening; e.g., Grillon et al., 2006, 2009) may elicit compensatory neuroadaptations within this same stress system. This within-system neuroadaptation may contribute to the sensitized response to unpredictable stressors observed in abstinent alcoholics (Gorka et al., 2013; Moberg et al., 2016). We hope these preliminary observations encourage reverse translational research to search for the neural mechanisms that could support this potential within-stress system adaption in rodent models (Koob et al., 2009; Sinha, Shaham, et al., 2011).

\section{Causes, Consequences, and Individual Differences in Stress Neuroadaptation}

Clearly, much work remains to more fully evaluate the rodent stress neuroadaptation thesis in humans. Cross-sectional research on participants with drug use disorders during periods of drug deprivation or early abstinence has provided preliminary support for the predicted phenotypic manifestation of stress neuroadaptations (Gorka et al., 2013; Hogle et al., 2010; Moberg et al., 2016). Alternatively, increased startle potentiation to unpredictable threats among participants with drug use disorders may represent a pre-morbid risk factor for addiction rather than the consequence of heavy, regular use (Gorka et al., 2016; Rasmussen and Kincaid, 2015). It is also possible that increased unpredictable startle potentiation among acutely drug deprived participants could represent short term perturbations in stress reactivity due to acute deprivation rather than more persistent stress neuroadaptations (Himmelsbach, 1941). These alternative explanations are not mutually exclusive. Longitudinal research is needed to document the temporal ordering of drug use and change in indices of stress neuroadaptations in humans.

Longitudinal research can more precisely identify the drug use characteristics most closely associated with the development of a stress neuroadaptation. Quantity of alcohol use did not predict the magnitude of the stress neuroadaptation among alcoholics in Moberg et al. 
(2016), but a more comprehensive assessment may be necessary to detect the impact of drinking quantity. Alternatively, rodent models suggest that particular patterns of drinking (e.g., repeated binging and withdrawal; Breese, 2005; Griffin et al., 2009; O’Dell et al., 2004) or contextual factors such as drug availability (e.g., extended access; Ahmed et al., 2000; Mantsch et al., 2008) rather than overall quantity may be necessary to promote or express allostatic changes in stressrelated neurocircuitry. In fact, Gorka et al., (2016) have recently observed that frequency of binge drinking in a community sample is positively associated with the magnitude of startle potentiation during unpredictable but not predictable threat. Gorka and colleague's observation combines with the rodent findings to strongly motivate longitudinal studies to identify risk factors in the development of stress neuroadaptation.

Longitudinal and other research is also necessary to evaluate the persistence of these stress neuroadaptations after cessation of drug use. Research has confirmed that stressors can instigate drug relapse well into protracted abstinence in rodents (Mantsch et al., 2016) and likely in humans as well (Brown et al., 1990; McKay, 1999). In Moberg et al., (2016) the putative stress neuroadaptations persisted for 2 months following cessation of alcohol use. In Gorka et al (2013), participants with co-morbid panic disorder that displayed selectively increased startle potentiation to unpredictable threat were in remission from alcohol dependence from at least one month to over one year. These studies suggest that the stress neuroadaptations persist well beyond acute deprivation into protracted abstinence. Future research with rodents that use startle potentiation to unpredictable threats during acute deprivation vs protracted abstinence may help to clarify the specificity and time-course of these stress neuroadaptations.

A careful examination of individual differences that impact the strength and developmental course for stress neuroadaptations following chronic drug use will also be 
necessary. For example, Hogle and Curtin (2006) observed increased startle potentiation (and salivary cortisol) among female but not male smokers who were nicotine deprived for 24 hours, consistent with proposals about sex differences in addiction etiology (Verplaetse et al., 2015). In other research, individuals who display increased general startle reactivity exhibit selectively greater startle potentiation to unpredictable threats (Bradford et al., 2014). Furthermore, these same individual differences in startle reactivity also moderate the effects of drug administration and deprivation on startle during unpredictable threats (Bradford et al., 2013; Hogle et al., 2010). Animal models are also well-positioned to test if naturally occurring individual differences in startle reactivity mark prospective risk for addiction (Rasmussen and Kincaid, 2015).

\section{Unpredictable Stressors across the Translational Spectrum}

Koob and others have highlighted the benefits of bi-directional translation between animal models and human clinical research on addiction (Koob et al., 2009; Sinha, Shaham, et al., 2011). Neurobiological targets that emerge from animal models feed forward to inform research on etiology and treatment in humans. Conversely, fundamental characteristics and symptoms of human addiction and its effective treatment should also feed backward to increase the validity of animal models such that they can further increase precision regarding neural mechanisms. We hope this review spurs reverse translation that focuses both on manipulations of stressor unpredictability and measurement of startle potentiation in animal addiction models. For example, unpredictable footshock robustly reinstates previously extinguished drug-seeking in rodents for all classes of additive drugs, but reinstatement has been far less consistently observed for other stressors that may be more predictable (e.g., food deprivation, swim stress, restraint; for review see Mantsch et al., 2016). Explicit contrast of predictable vs. unpredictable stressors in 
stress-induced reinstatement models in rodents is needed to confirm this prediction about stressor unpredictability (see also Mantsch et al., 2016, p. 339).

To our knowledge, NPU-like tasks that measure startle potentiation have not been widely used in animal addiction models to date. Individual differences in these tasks should be examined pre-drug exposure to predict subsequent initiation, escalation, and/or relapse risk (for example see Rasmussen and Kincaid, 2015). Similarly, these tasks can be administered in drug dependent animals during early acute deprivation and protracted abstinence to establish the specific uncertain threat adaptation in rodents and probe its time course. CRF and NE antagonists could also be administered in these NPU-like tasks with rodents to directly connect to clinical trials using this surrogate endpoint in humans.

More generally, much work remains to clearly define the unpredictability construct and parse it from related constructs. At this point, it appears possible to develop clear, a priori laboratory manipulations of unpredictability in rodents and humans but it remains more challenging to prospectively identify and categorize real world stressors as unpredictable vs. predictable. The relatively consistent effects of alcohol administration we observed across diverse manipulations of unpredictability suggest a broad construct that spans uncertainty about if, when, where, and how bad the threat will be (Figure 3). Davis and colleagues have noted that unpredictable vs. predictable stressors typically elicit temporally distinct sustained vs. phasic response, respectively (Davis et al., 2010). It is true that temporally unpredictable shock threat in the NPU task elicits sustained startle potentiation (Grillon et al., 2004; Moberg and Curtin, 2009). However, temporally precise shock administration that is unpredictable with respect to probability, intensity, or location produces more phasic startle potentiation that is still selectively reduced by alcohol administration (Bradford et al., in prep, 2013; Hefner and Curtin, 2012). Use 
of these tasks with rodents may allow for additional parsing of the mechanisms related to unpredictability vs. the time course of responding.

Unpredictability and uncontrollability are closely related constructs but stressor controllability has yet to be adequately studied in stress neuroadaptation models of addiction. When stressors are unpredictable, they are also generally uncontrollable. Uncontrollability has been implicated in affective disturbance including anxiety and in particular, depression, which is also highly co-morbid with drug use disorders (Maier, 2015). In a parallel line of research with rodents, Maier and colleagues have suggested that response to uncontrollable stressors is partially mediated by $\mathrm{CRF}$ and NE mechanisms, similar to unpredictable stressors (Hammack et al., 2004; Maier, 2015). This focus on stressor controllability that has been prominent in rodent models of depression (e.g., learned helplessness/resilience; Maier and Seligman, 1976, 2016) has been notably absent from rodent models of stress-induced reinstatement. Experimental designs that disentangle stressor unpredictability and uncontrollability are needed to parse these constructs and their etiological mechanisms in addiction and relapse in both rodents and humans.

\section{Psychosocial Treatments Viewed through the Lens of Unpredictable Stressors}

Earlier, we reviewed medication development within the experimental therapeutics paradigm to address neurotransmitter mechanisms involved in response to unpredictable stressors. Of course, treatment development efforts to target unpredictable stressors do not need to be focused only on medications. More precise targeting of sources and coping strategies for unpredictable stressors may increase the efficacy of psychological interventions for addiction. Relapse prevention programs can help patients to better identify risks by explicit, personalized assessment of the stressors in their lives that are both potent but also characterized by a high degree of uncertainty. These programs can also help patients develop tools to reshape their 
environments and social interactions to reduce unpredictability (e.g., problem-solving to address uncertain financial, housing, or interpersonal stresses; practice direct communication with partners, peers, and others to clarify stressful but ambiguous interpersonal exchanges). Patients can also be alerted to seek additional support during periods of high unpredictability with associated high relapse risk, when efforts to reduce these risks are unsuccessful or not possible (e.g., health crises where likely outcomes may not be immediately known).

This focus on unpredictable stressors also reinforces the potential benefits offered by existing but often unavailable or underfunded harm reduction approaches. These programs can robustly reduce uncertainty for drug dependent users regarding some of the most potent and unpredictable stressors involving housing, health, and other basic needs (Newman and Goldman, 2008). For example, harm reduction approaches such as Housing First (Davidson et al., 2014), needle exchange programs (Ksobiech, 2003), and medication-assisted therapies such as opiate substitution (Amato et al., 2005) can substantially reduce these salient but unpredictable stressors and they have been shown to significantly improve substance use outcomes. 


\section{Acknowledgments}

Research reported in this publication was supported by the National Institute of Alcohol Abuse and Alcoholism (R01-AA024388; R01-AA15384; F31-AA022845) and National Institute of Drug Abuse (R01-DA033809). The content is solely the responsibility of the authors and does not necessarily represent the official views of the National Institutes of Health. 


\section{References}

al'Absi, M. (2006). Hypothalamic-pituitary-adrenocortical responses to psychological stress and risk for smoking relapse. International Journal of Psychophysiology, 59(3), 218-227. doi: 10.1016/j.ijpsycho.2005.10.010

Ahmed, S. H., Walker, J. R., and Koob, G. F. (2000). Persistent increase in the motivation to take heroin in rats with a history of drug escalation. Neuropsychopharmacology, 22(4), 413-421. doi: 10.1016/S0893-133X(99)00133-5

Alheid, G. F., and Heimer, L. (1988). New perspectives in basal forebrain organization of special relevance for neuropsychiatric disorders: The striatopallidal, amygdaloid, and corticopetal components of substantia innominata. Neuroscience, 27(1), 1-39.

Alvarez, R. P., Chen, G., Bodurka, J., Kaplan, R., and Grillon, C. (2011). Phasic and sustained fear in humans elicits distinct patterns of brain activity. NeuroImage, 55(1), 389-400. doi: 10.1016/j.neuroimage.2010.11.057

Amato, L., Davoli, M., Perucci, C. A., Ferri, M., Faggiano, F., and Mattick, R. P. (2005). An overview of systematic reviews of the effectiveness of opiate maintenance therapies: available evidence to inform clinical practice and research. Journal of Substance Abuse Treatment, 28(4), 321-329. doi: 10.1016/j.jsat.2005.02.007

Arnsten, A. F. T. (2009). Stress signalling pathways that impair prefrontal cortex structure and function. Nature reviews. Neuroscience, 10(6), 410-422. doi: 10.1038/nrn2648

Aston-Jones, G., and Harris, G. (2004). Brain substrates for increased drug seeking during protracted withdrawal. Neuropharmacology, 47 Suppl 1, 167-79. doi: 10.1016/j.neuropharm.2004.06.020 
Avery, S. N., Clauss, J. A., and Blackford, J. U. (2016). The Human BNST: Functional Role in Anxiety and Addiction. Neuropsychopharmacology, 41(1), 126-141. doi: 10.1038/npp.2015.185

Baas, J. M., Grillon, C., Böcker, K. B. E., Brack, A. A., Morgan, C. A., Kenemans, J. L., and Verbaten, M. N. (2002). Benzodiazepines have no effect on fear-potentiated startle in humans. Psychopharmacology, 161(3), 233-247.

Back, S. E., K. Hartwell, DeSantis, S. M., Saladin, M., McRae-Clark, A. L., Price, K. L., MoranSanta Maria, M. M., et al. (2010). Reactivity to laboratory stress provocation predicts relapse to cocaine. Drug and Alcohol Dependence, 106(1), 21-27. doi: 10.1016/j.drugalcdep.2009.07.016

Badiani, A., Belin, D., Epstein, D., Calu, D., and Shaham, Y. (2011). Opiate versus psychostimulant addiction: the differences do matter. Nature Reviews Neuroscience, 12(11), 685-700. doi: 10.1038/nrn3104

Baker, T. B., Piper, M. E., McCarthy, D. E., Majeskie, M. R., and Fiore, M. C. (2004). Addiction motivation reformulated: an affective processing model of negative reinforcement. Psychological Review, 111(1), 33-51.

Baldwin, H. A., Rassnick, S., Rivier, J., and Koob, G. F. (1991). CRF antagonist reverses the "anxiogenic" response to ethanol withdrawal in the rat. Psychopharmacology, 103(2), $227-232$.

Bale, T. L., and Vale, W. W. (2004). CRF and CRF receptors: Role in Stress Responsivity and Other Behaviors. Annual Review of Pharmacology and Toxicology, 44(1), 525-557. doi: 10.1146/annurev.pharmtox.44.101802.121410 
Binneman, B., Feltner, D., Kolluri, S., Shi, Y., Qiu, R., and Stiger, T. (2008). A 6-week randomized, placebo-controlled trial of CP-316,311 (a selective CRH1 antagonist) in the treatment of major depression. American Journal of Psychiatry, 165(5), 617-620.

Bradford, D. E., Kaye, J. T., and Curtin, J. J. (2014). Not just noise: individual differences in general startle reactivity predict startle response to uncertain and certain threat. Psychophysiology, 51(5), 407-411. doi: 10.1111/psyp.12193

Bradford, D. E., Shapiro, B. L., and Curtin, J. J. (2013). How bad could it be? Alcohol dampens stress responses to threat of uncertain intensity. Psychological science, 24(12), 25412549. doi: $10.1177 / 0956797613499923$

Bradford, D. E., Starr, M. J., Motschman, C. A., and Curtin, J. J. (in prep). Alcohol dose dependently dampens increased attention, defensive reactivity, and subjective anxiety to unpredictable stressors. Manuscript in preparation.

Breese, G. R. (2005). Conceptual framework for the etiology of alcoholism: a "kindling"/stress hypothesis. Psychopharmacology, (178), 367-380. doi: 10/1007/s00213-004-2016-2

Breese, G. R., Sinha, R., and Heilig, M. (2011). Chronic alcohol neuroadaptation and stress contribute to susceptibility for alcohol craving and relapse. Pharmacology \& Therapeutics, 129(2), 149-171. doi: 10.1016/j.pharmthera.2010.09.007

Brown, S. A., Vik, P. W., McQuaid, J. R., Patterson, T. L., Irwin, M. R., and Grant, I. (1990). Severity of psychosocial stress and outcome of alcoholism treatment. Journal of Abnormal Psychology, 99(4), 344-348.

Brown, Z., Tribe, E., D'souza, N., and Erb, S. (2009). Interaction between noradrenaline and corticotrophin-releasing factor in the reinstatement of cocaine seeking in the rat. Psychopharmacology, 203(1), 121-130. doi: 10.1007/s00213-008-1376-4 
Bruijnzeel, A. W., Prado, M., and Isaac, S. (2009). Corticotropin-releasing factor-1 receptor activation mediates nicotine withdrawal-induced deficit in brain reward function and stress-induced relapse. Biological psychiatry, 66(2), 110-117. doi:

10/1016/j.biopsych.2009.01.010

Buczek, Y., Le, A. D., Stewart, J., and Shaham, Y. (1999). Stress reinstates nicotine seeking but not sucrose solution seeking in rats. Psychopharmacology (Berl), 144(2), 183-8.

Button, K. S., Ioannidis, J. P. A., Mokrysz, C., Nosek, B. A., Flint, J., Robinson, E. S. J., and Munafò, M. R. (2013). Power failure: why small sample size undermines the reliability of neuroscience. Nature Reviews Neuroscience, 14(5), 365-376. doi: 10.1038/nrn3475

Campeau, S., Hayward, M. D., Hope, B. T., Rosen, J. B., Nestler, E. J., and Davis, M. (1991). Induction of the c-fos proto-oncogene in rat amygdala during unconditioned and conditioned fear. Brain Research, 565(2), 349-352.

Chen, Y.-W., Fiscella, K. A., Bacharach, S. Z., Tanda, G., Shaham, Y., and Calu, D. J. (2015). Effect of yohimbine on reinstatement of operant responding in rats is dependent on cue contingency but not food reward history. Addiction biology, 20(4), 690-700. doi: 10.1111/adb.12164

Cooper, M. L., Frone, M. R., Russell, M., and Mudar, P. (1995). Drinking to regulate positive and negative emotions: A motivational model of alcohol use. Journal of Personality \& Social Psychology, 69(5), 990-1005.

Coric, V., Feldman, H. H., Oren, D. A., Shekhar, A., Pultz, J., Dockens, R. C., Wu, X., et al. (2010). Multicenter, randomized, double-blind, active comparator and placebo-controlled trial of a corticotropin-releasing factor receptor-1 antagonist in generalized anxiety disorder. Depression and anxiety, 27(5), 417-425. doi: 10/1002/da.20695 
Curtin, J. J., Baker, T. B., Piper, M. E., and Bolt, D. M. (2012). NIDA R01: Clinical relevance of stress neuroadaptation in tobacco dependence. Retrieved June 16, 2016, from https://osf.io/pk86j/

Curtin, J. J., Kaye, J. T., Berridge, C. W., and Zgierska, A. (2015). NIAAA R01: Randomized controlled trial targeting noradrenergic stress mechanisms in alcoholism with doxazosin. Retrieved March 24, 2016, from https://osf.io/w7urh/

Curtin, J. J., and Lang, A. R. (2007). Alcohol and emotion: Insights and directives from affective science. Emotion and Psychopathology: Bridging Affective and Clinical Science, 8, 191213.

Davidson, C., Neighbors, C., Hall, G., Hogue, A., Cho, R., Kutner, B., and Morgenstern, J. (2014). Association of housing first implementation and key outcomes among homeless persons with problematic substance use. Psychiatric Services (Washington, D.C.), 65(11), 1318-1324. doi: 10.1176/appi.ps.201300195

Davis, M. (2006). Neural systems involved in fear and anxiety measured with fear-potentiated startle. American Psychologist, 61(8), 741-756. doi: 10.1037/0003-066X.61.8.741

Davis, M., Antoniadis, E., Amaral, D., and Winslow, J. (2008). Acoustic startle reflex in rhesus monkeys: A review. Reviews in the Neurosciences, 19, 171-185. doi: 10.1515/REVNEURO.2008.19.2-3.171

Davis, M., Walker, D. L., Miles, L., and Grillon, C. (2010). Phasic vs sustained fear in rats and humans: Role of the extended amygdala in fear vs anxiety. Neuropsychopharmacology Reviews, 35(1), 105-135. doi: doi:10.1037/npp.2009

Day, H. E., Curran, E. J., Watson, S. J., and Akil, H. (1999). Distinct neurochemical populations in the rat central nucleus of the amygdala and bed nucleus of the stria terminalis: 
evidence for their selective activation by interleukin-1beta. The Journal of Comparative Neurology, 413(1), 113-128.

Dong, H. W., Petrovich, G. D., and Swanson, L. W. (2001). Topography of projections from amygdala to bed nuclei of the stria terminalis. Brain Research. Brain Research Reviews, 38(1-2), 192-246. doi: 10/1016/S0165-0173(01)00079-0

Endres, T., Apfelbach, R., and Fendt, M. (2005). Behavioral changes induced in rats by exposure to trimethylthiazoline, a component of fox odor. Behavioral Neuroscience, 119(4), 10041010. doi: 10.1037/0735-7044.119.4.1004

Erb, S. (2010). Evaluation of the relationship between anxiety during withdrawal and stressinduced reinstatement of cocaine seeking. Progress in Neuro-Psychopharmacology \& Biological Psychiatry, 34(5), 798-807. doi: 10.1016/j.pnpbp.2009.11.025

Erb, S., Hitchcott, P. K., Rajabi, H., Mueller, D., Shaham, Y., and Stewart, J. (2000). Alpha-2 adrenergic receptor agonists block stress-induced reinstatement of cocaine seeking. Neuropsychopharmacology, 23(2), 138-150. doi: 10.1016/S0893-133X(99)00158-X

Erb, S., Salmaso, N., Rodaros, D., and Stewart, J. (2001). A role for the CRF-containing pathway from central nucleus of the amygdala to bed nucleus of the stria terminalis in the stressinduced reinstatement of cocaine seeking in rats. Psychopharmacology, 158(4), 360-365. doi: $10.1007 / \mathrm{s} 002130000642$

Erb, S., Shaham, Y., and Stewart, J. (1996). Stress reinstates cocaine-seeking behavior after prolonged extinction and a drug-free period. Psychopharmacology, 128(4), 408-412.

Erb, S., and Stewart, J. (1999). A role for the bed nucleus of the stria terminalis, but not the amygdala, in the effects of corticotropin-releasing factor on stress-induced reinstatement of cocaine seeking. The Journal of Neuroscience, 19(20), RC35. 
España, R. A., Schmeichel, B. E., and Berridge, C. W. (2016). Norepinephrine at the nexus of arousal, motivation and relapse. Brain Research, 1641(Pt B), 207-216. doi: 10.1016/j.brainres.2016.01.002

Feltenstein, M. W., Ghee, S. M., and See, R. E. (2012). Nicotine self-administration and reinstatement of nicotine-seeking in male and female rats. Drug and alcohol dependence, 121(3), 240-246. doi: 10.1016/j.drugalcdep.2011.09.001

Fox, A. S., Oler, J. A., Tromp, D. P. M., Fudge, J. L., and Kalin, N. H. (2015). Extending the amygdala in theories of threat processing. Trends in Neurosciences, 38(5), 319-329. doi: 10.1016/j.tins.2015.03.002

Fox, H. C., Anderson, G. M., Tuit, K., Hansen, J., Kimmerling, A., Siedlarz, K. M., Morgan, P. T., et al. (2012). Prazosin effects on stress- and cue-induced craving and stress response in alcohol-dependent individuals: preliminary findings. Alcoholism, Clinical and Experimental Research, 36(2), 351-360. doi: 10.1111/j.1530-0277.2011.01628.x

Fox, H. C., Morgan, P. T., and Sinha, R. (2014). Sex differences in guanfacine effects on drug craving and stress arousal in cocaine-dependent individuals. Neuropsychopharmacology: Official Publication of the American College of Neuropsychopharmacology, 39(6), 15271537. doi: $10.1038 / n p p .2014 .1$

Fox, H. C., Seo, D., Tuit, K., Hansen, J., Kimmerling, A., Morgan, P. T., and Sinha, R. (2012). Guanfacine effects on stress, drug craving and prefrontal activation in cocaine dependent individuals: preliminary findings. Journal of Psychopharmacology (Oxford, England), 26(7), 958-972. doi: 10.1177/0269881111430746 
Funk, D., Coen, K., Tamadon, S., Li, Z., Loughlin, A., and Lê, A. D. (2016). Effects of prazosin and doxazosin on yohimbine-induced reinstatement of alcohol seeking in rats. Psychopharmacology. doi: 10.1007/s00213-016-4273-2

Gehlert, D. R., Cippitelli, A., Thorsell, A., Lê, A. D., Hipskind, P. A., Hamdouchi, C., Lu, J., et al. (2007). 3-(4-Chloro-2-morpholin-4-yl-thiazol-5-yl)-8-(1-ethylpropyl)-2,6-dimethylimidazo[1,2-b]pyridazine: a novel brain-penetrant, orally available corticotropinreleasing factor receptor 1 antagonist with efficacy in animal models of alcoholism. The Journal of Neuroscience, 27(10), 2718-2726. doi: 10.1523/JNEUROSCI.4985-06.2007

George, O., Ghozland, S., Azar, M. R., Cottone, P., Zorrilla, E. P., Parsons, L. H., O’Dell, L. E., et al. (2007). CRF-CRF1 system activation mediates withdrawal induced increases in nicotine self-administration in nicotine-dependent rats. Proceedings of the National Academy of Sciences, 104(43), 17198-17203. doi: 10.1073/pnas.0707585104

Giardino, W. J., and Ryabinin, A. E. (2012). Corticotropin-releasing factor: innocent until proven guilty. Nat Rev Neurosci, 13(1), 70. doi: 10.1038/nrn3110-c1

Gorka, S. M., Lieberman, L., Phan, K. L., and Shankman, S. A. (2016). Association between problematic alcohol use and reactivity to uncertain threat in two independent samples. Drug and Alcohol Dependence. doi: 10.1016/j.drugalcdep.2016.04.034

Gorka, S. M., Nelson, B. D., and Shankman, S. A. (2013). Startle response to unpredictable threat in comorbid panic disorder and alcohol dependence. Drug and Alcohol Dependence, 132(1-2), 216-222. doi: 10.1016/j.drugalcdep.2013.02.003

Grant, B. F., Saha, T. D., Ruan, J., and et al. (2016). Epidemiology of dsm-5 drug use disorder: Results from the national epidemiologic survey on alcohol and related conditions-iii. JAMA Psychiatry, 73(1), 39-47. doi: 10.1001/jamapsychiatry.2015.2132 
Gray, T. S., and Magnuson, D. J. (1987). Neuropeptide neuronal efferents from the bed nucleus of the stria terminalis and central amygdaloid nucleus to the dorsal vagal complex in the rat. The Journal of Comparative Neurology, 262(3), 365-374. doi:

10.1002/cne.902620304

Gresack, J., and Risbrough, V. (2011). Corticotropin-releasing factor and noradrenergic signalling exert reciprocal control over startle reactivity. The International Journal of Neuropsychopharmacology, 14(9), 1179-94. doi: 10.1017/S1461145710001409

Griffin, W. C., Lopez, M. F., and Becker, H. C. (2009). Intensity and duration of chronic ethanol exposure is critical for subsequent escalation of voluntary ethanol drinking in mice. Alcoholism, Clinical and Experimental Research, 33(11), 1893-1900. doi: 10.1111/j.1530-0277.2009.01027.x

Grillon, C. (2008). Models and mechanisms of anxiety: evidence from startle studies. Psychopharmacology, 199(3), 421-437. doi: 10.1007/s00213-007-1019-1

Grillon, C., Ameli, R., Woods, S. W., and Merikangas, K. (1991). Fear-potentiated startle in humans: Effects of anticipatory anxiety on the acoustic blink reflex. Psychophysiology, $28(5), 588-595$.

Grillon, C., Avenevoli, S., Daurignac, E., and Merikangas, K. R. (2007). Fear-potentiated startle to threat, and prepulse inhibition among young adult nonsmokers, abstinent smokers, and nonabstinent smokers. Biological Psychiatry, 62, 1155-1161. doi: 10/1016/j.biopsych.2006.12.027

Grillon, C., Baas, J. M., Lissek, S., Smith, K., and Milstein, J. (2004). Anxious responses to predictable and unpredictable aversive events. Behavioral Neuroscience, 118(5), 916924. doi: 10.1037/0735-7044.118.5.916 
Grillon, C., Baas, J. M., Pine, D. S., Lissek, S., Lawley, M., Ellis, V., and Levine, J. (2006). The benzodiazepine alprazolam dissociates contextual fear from cued fear in humans as assessed by fear-potentiated startle. Biological Psychiatry, 60(7), 760-766. doi: 10/1016/j.biopsych.2005.11.027

Grillon, C., Chavis, C., Covington, M. F., and Pine, D. S. (2009). Two-week treatment with the selective serotonin reuptake inhibitor citalopram reduces contextual anxiety but not cued fear in healthy volunteers: A fear-potentiated startle study. Neuropsychopharmacology, 34(4), 964-971. doi: 10.1038/npp.2008.141

Grillon, C., and Davis, M. (1997). Fear-potentiated startle conditioning in humans: explicit and contextual cue conditioning following paired versus unpaired training. Psychophysiology, $34(4), 451-8$.

Grillon, C., Hale, E., Lieberman, L., Davis, A., Pine, D. S., and Ernst, M. (2015). The CRH1 Antagonist GSK561679 Increases Human Fear But Not Anxiety as Assessed by Startle. Neuropsychopharmacology, 40(5), 1064-1071. doi: 10.1038/npp.2014.316

Grillon, C., Heller, R., Hirschhorn, E., Kling, M. A., Pine, D. S., Schulkin, J., and Vythilingam, M. (2011). Acute Hydrocortisone Treatment Increases Anxiety but Not Fear in Healthy Volunteers: A Fear-Potentiated Startle Study. Biological Psychiatry, 69(6), 549-555. doi: 10.1016/j.biopsych.2010.12.013

Grillon, C., Levenson, J., and Pine, D. S. (2007). A single dose of the selective serotonin reuptake inhibitor citalopram exacerbates anxiety in humans: a fear-potentiated startle study. Neuropsychopharmacology, 32(1), 225-231. doi: 10.1038/sj.npp.1301204

Grillon, C., Pellowski, M., Merikangas, K. R., and Davis, M. (1997). Darkness facilitates the acoustic startle reflex in humans. Biological Psychiatry, 42(6), 453-460. 
Hammack, S. E., Richey, K. J., Watkins, L. R., and Maier, S. F. (2004). Chemical lesion of the bed nucleus of the stria terminalis blocks the behavioral consequences of uncontrollable stress. Behavioral Neuroscience, 118(2), 443-448. doi: 10.1037/0735-7044.118.2.443

Harris, G. C., and Aston-Jones, G. (1993). Beta-adrenergic antagonists attenuate withdrawal anxiety in cocaine- and morphine-dependent rats. Psychopharmacology, 113(1), 131136.

Hefner, K. R., and Curtin, J. J. (2012). Alcohol stress response dampening: Selective reduction of anxiety in the face of uncertain threat. Journal of Psychopharmacology, 26(2), 232244. doi: $10.1177 / 0269881111416691$

Hefner, K. R., Moberg, C. A., Hachiya, L. Y., and Curtin, J. J. (2013). Alcohol stress response dampening during imminent versus distal, uncertain threat. Journal of Abnormal Psychology, 122(3), 756-769. doi: 10.1037/a0033407

Hefner, K. R., Starr, M. J., and Curtin, J. J. (in prep). Increased stress response to threat among heavy marijuana users.

Heilig, M. (2012). Our focus on the pharmacogenetics of CRF1 antagonists is simply because they are in clinical development. Nature Reviews Neuroscience, 13(1), 70. doi: $10.1038 / \mathrm{nrn} 3110-\mathrm{c} 2$

Heilig, M., Egli, M., Crabbe, J. C., and Becker, H. C. (2010). Acute withdrawal, protracted abstinence and negative affect in alcoholism: are they linked? Addiction Biology, 15(2), 169-184. doi: 10.1111/j.1369-1600.2009.00194.x

Heilig, M., Goldman, D., Berrettini, W., and O’Brien, C. P. (2011). Pharmacogenetic approaches to the treatment of alcohol addiction. Nature Reviews Neuroscience, 12(11), 670-684. doi: $10.1038 / \mathrm{nrn} 3110$ 
Himmelsbach, C. K. (1941). Studies on the relation of drug addiction to the autonomic nervous system: Results of cold pressor tests. Journal of Pharmacology and Experimental Therapeutics, 73(1), 91-98.

Hitchcock, J. M., and Davis, M. (1991). Efferent pathway of the amygdala involved in conditioned fear as measured with the fear-potentiated startle paradigm. Behavioral Neuroscience, 105(6), 826-842.

Hogle, J. M., and Curtin, J. J. (2006). Sex differences in negative affective response during nicotine withdrawal. Psychophysiology, 43(4), 344-356. doi: 10.1111/j.14692006.00406.x

Hogle, J. M., Kaye, J. T., and Curtin, J. J. (2010). Nicotine withdrawal increases threat-induced anxiety but not fear: Neuroadaptation in human addiction. Biological Psychiatry, 68(8), 687-688. doi: 10.1016/j.biopsych.2010.06.003

Insel, T. R. (2012). Next-generation treatments for mental disorders. Sci Transl Med, 4(155), 155ps19. doi: 10.1126/scitranslmed.3004873

Insel, T. R. (2015). The NIMH experimental medicine initiative. World psychiatry, 14(2), 151153. doi: $10.1002 / w p s .20227$

Insel, T. R., and Gogtay, N. (2014). National Institute of Mental Health clinical trials: new opportunities, new expectations. JAMA psychiatry, 71(7), 745-746. doi: 10.1001/jamapsychiatry.2014.426

Ioannidis, J. P. A. (2005). Why most published research findings are false. PLoS medicine, 2(8), e124. doi: 10.1371/journal.pmed.0020124 
Jobes, M. L., Ghitza, U. E., Epstein, D. H., Phillips, K. A., Heishman, S. J., and Preston, K. L. (2011). Clonidine blocks stress-induced craving in cocaine users. Psychopharmacology, 218(1), 83-88. doi: 10.1007/s00213-011-2230-7

de Jongh, R., Groenink, L., van der Gugten, J., and Olivier, B. (2003). Light-enhanced and fearpotentiated startle: temporal characteristics and effects of alpha-helical corticotropinreleasing hormone. Biological Psychiatry, 54(10), 1041-1048. doi: 10/1016/S0006$3223(03) 00468-2$

Jonkman, S., Risbrough, V. B., Geyer, M. A., and Markou, A. (2007). Spontaneous nicotine withdrawal potentiates the effects of stress in rats. Neuropsychopharmacology, 33(9), 2131-8. doi: 10/1038/sj.npp.1301607

Kapur, S., Phillips, A. G., and Insel, T. R. (2012). Why has it taken so long for biological psychiatry to develop clinical tests and what to do about it? Molecular Psychiatry, 17(12), 1174-1179. doi: 10.1038/mp.2012.105

Kassel, J. D., Stroud, L. R., and Paronis, C. A. (2003). Smoking, stress, and negative affect: correlation, causation, and context across stages of smoking. Psychological bulletin, 129(2), 270-304.

Kaye, J. T., Bradford, D. E., and Curtin, J. J. (2016). Psychometric properties of startle and corrugator response in NPU, affective picture viewing, and resting state tasks. Psychophysiology, 53(8), 1241-1255. doi: 10.1111/psyp.12663

Kehne, J. H., and Davis, M. (1985). Central noradrenergic involvement in yohimbine excitation of acoustic startle: effects of DSP4 and 6-OHDA. Brain Research, 330(1), 31-41. 
Kenna, G. A., Haass-Koffler, C. L., Zywiak, W. H., Edwards, S. M., Brickley, M. B., Swift, R. M., and Leggio, L. (2015). Role of the $\alpha 1$ blocker doxazosin in alcoholism: a proof-ofconcept randomized controlled trial. Addiction Biology. doi: 10.1111/adb.12275

Koob, G. F. (2009). Brain stress systems in the amygdala and addiction. Brain Research, 1293, 61-75. doi: 10.1016/j.brainres.2009.03.038

Koob, G. F. (2010). The role of CRF and CRF-related peptides in the dark side of addiction. Brain Research, 1314, 3-14. doi: 10.1016/j.brainres.2009.11.008

Koob, G. F. (2013). Addiction is a reward deficit and stress surfeit disorder. Frontiers in Addictive Disorders and Behavioral Dyscontrol, 4, 72. doi: 10.3389/fpsyt.2013.00072

Koob, G. F. (2015). The darkness within: Individual differences in stress. Cerebrum: the Dana Forum on Brain Science, 2015. Retrieved from http://www.ncbi.nlm.nih.gov/pmc/articles/PMC4445593/

Koob, G. F., and Bloom, F. E. (1988). Cellular and Molecular Mechanisms of Drug Dependence. Science, 242(4879), 715-723.

Koob, G. F., and Le Moal, M. (2008a). Addiction and the Brain Antireward System. Annual Review of Psychology, 59, 29-53. doi: 10/1146/annurev.psych.59.103006.093548

Koob, G. F., and Le Moal, M. (2008b). Neurobiological mechanisms for opponent motivational processes in addiction. Phil. Trans. R. Soc. B, 363(1507), 3113-3123. doi: 10/1098/rstb.2008.0094

Koob, G. F., Lloyd, G. K., and Mason, B. J. (2009). Development of pharmacotherapies for drug addiction: a Rosetta Stone approach. Nature Reviews Drug Discovery, 8(6), 500-515. doi: $10.1038 / \mathrm{nrd} 2828$ 
Koob, G. F., and Zorrilla, E. P. (2012). Update on corticotropin-releasing factor pharmacotherapy for psychiatric disorders: a revisionist view. Neuropsychopharmacology, 37(1), 308-309. doi: 10.1038/npp.2011.213

Ksobiech, K. (2003). A meta-analysis of needle sharing, lending, and borrowing behaviors of needle exchange program attenders. AIDS education and prevention, 15(3), 257-268.

Kwako, L. E., Schwandt, M. L., Sells, J. R., Ramchandani, V. A., Hommer, D. W., George, D. T., Sinha, R., et al. (2015). Methods for inducing alcohol craving in individuals with comorbid alcohol dependence and posttraumatic stress disorder: behavioral and physiological outcomes. Addiction Biology, 20(4), 733-746. doi: 10.1111/adb.12150

Kwako, L. E., Spagnolo, P. A., Schwandt, M. L., Thorsell, A., George, D. T., Momenan, R., Rio, D. E., et al. (2015). The corticotropin releasing hormone-1 (CRH1) receptor antagonist pexacerfont in alcohol dependence: a randomized controlled experimental medicine study. Neuropsychopharmacology, 40(5), 1053-1063. doi: 10.1038/npp.2014.306

Lê, A. D., Funk, D., Juzytsch, W., Coen, K., Navarre, B., Cifani, C., and Shaham, Y. (2011). Effect of prazosin and guanfacine on stress-induced reinstatement of alcohol and food seeking in rats. Psychopharmacology, 218(1), 89-99. doi: 10.1007/s00213-011-2178-7

Lê, A. D., Harding, S., Juzytsch, W., Funk, D., and Shaham, Y. (2005). Role of alpha-2 adrenoceptors in stress-induced reinstatement of alcohol seeking and alcohol selfadministration in rats. Psychopharmacology, 179(2), 366-373. doi: 10.1007/s00213-0042036-y

Lê, A. D., Harding, S., Juzytsch, W., Watchus, J., Shalev, U., and Shaham, Y. (2000). The role of corticotrophin-releasing factor in stress-induced relapse to alcohol-seeking behavior in rats. Psychopharmacology, 150, 317-324. 
Lê, A. D., Quan, B., Juzytch, W., Fletcher, P. J., Joharchi, N., and Shaham, Y. (1998).

Reinstatement of alcohol-seeking by priming injections of alcohol and exposure to stress in rats. Psychopharmacology, 135, 169-174.

Lee, Y., and Davis, M. (1997). Role of the hippocampus, the bed nucleus of the stria terminalis, and the amygdala in the excitatory effect of corticotropin-releasing hormone on the acoustic startle reflex. Journal of Neuroscience, 17(16), 6434-6446.

Lerman, C., LeSage, M. G., Perkins, K. A., O’Malley, S. S., Siegel, S. J., Benowitz, N. L., and Corrigall, W. A. (2007). Translational research in medication development for nicotine dependence. Nature Reviews. Drug Discovery, 6(9), 746-762. doi: 10.1038/nrd2361

Liang, K. C., Melia, K. R., Miserendino, M. J., Falls, W. A., Campeau, S., and Davis, M. (1992). Corticotropin-releasing factor: long-lasting facilitation of the acoustic startle reflex. The Journal of Neuroscience, 12(6), 2303-2312.

Litten, R. Z., Falk, D. E., Ryan, M. L., and Fertig, J. B. (2016). Discovery, development, and adoption of medications to treat alcohol use disorder: Goals for the phases of medications development. Alcoholism: Clinical and Experimental Research, 40(7), 1368-1379. doi: 10.1111/acer.13093

Mahler, S. V., Smith, R. J., Moorman, D. E., Sartor, G. C., and Aston-Jones, G. (2012). Multiple roles for orexin/hypocretin in addiction. Progress in Brain Research, 198, 79-121. doi: 10.1016/B978-0-444-59489-1.00007-0

Maier, S. F. (2015). Behavioral control blunts reactions to contemporaneous and future adverse events: medial prefrontal cortex plasticity and a corticostriatal network. Neurobiology of Stress, 1, 12-22. doi: 10.1016/j.ynstr.2014.09.003 
Maier, S. F., and Seligman, M. E. (1976). Learned helplessness: Theory and evidence. Journal of Experimental Psychology: General, 105(1), 3-46. doi: 10.1037/0096-3445.105.1.3

Maier, S. F., and Seligman, M. E. P. (2016). Learned helplessness at fifty: Insights from neuroscience. Psychological Review, 123(4), 349-367. doi: 10.1037/rev0000033

Manion, S., Gamble, E., and Li, H. (2007). Prazosin administered prior to inescapable stressor blocks subsequent exaggeration of acoustic startle response in rats. Pharmacology, biochemistry, and behavior, 86(3), 559-65. doi: 10.1016/j.pbb.2007.01.019

Mantsch, J. R., Baker, D. A., Francis, D. M., Katz, E. S., Hoks, M. A., and Serge, J. P. (2008). Stressor- and corticotropin releasing factor-induced reinstatement and active stressrelated behavioral responses are augmented following long-access cocaine selfadministration by rats. Psychopharmacology, 195(4), 591-603. doi: 10.1007/s00213-0070950-5

Mantsch, J. R., Baker, D. A., Funk, D., Lê, A. D., and Shaham, Y. (2016). Stress-Induced Reinstatement of Drug Seeking: 20 Years of Progress. Neuropsychopharmacology, 41(1), 335-356. doi: 10.1038/npp.2015.142

McCarthy, E., and Petrakis, I. (2010). Epidemiology and management of alcohol dependence in individuals with post-traumatic stress disorder. CNS drugs, 24(12), 997-1007. doi: $10.2165 / 11539710-000000000-00000$

McEwen, B. S., and Gianaros, P. J. (2011). Stress- and allostasis-induced brain plasticity. Annual Review of Medicine, 62, 431-445. doi: 10.1146/annurev-med-052209-100430

McKay, J. R. (1999). Studies of factors in relapse to alcohol, drug and nicotine use: a critical review of methodologies and findings. Journal of Studies on Alcohol, 60(4), 566-576. 
McKee, S. A. (2009). Developing human laboratory models of smoking lapse behavior for medication screening. Addiction Biology, 14(1), 99-107. doi: 10.1111/j.13691600.2008.00135.x

McKee, S. A., Potenza, M. N., Kober, H., Sofuoglu, M., Arnsten, A. F. T., Picciotto, M. R., Weinberger, A. H., et al. (2015). A translational investigation targeting stress-reactivity and prefrontal cognitive control with guanfacine for smoking cessation. Journal of Psychopharmacology (Oxford, England), 29(3), 300-311. doi:

\section{$10.1177 / 0269881114562091$}

Miller, G. (2010). Is pharma running out of brainy ideas? Science (New York, NY), 329(5991), 502-4. doi: 10.1126/science.329.5991.502

Moberg, C. A., Bradford, D. E., Kaye, J. T., and Curtin, J. J. (2016). Increased startle potentiation to unpredictable stressors in alcohol dependence: Stress neuroadaptation in humans. Clinical Psychological Science, Manuscript under review.

Moberg, C. A., and Curtin, J. J. (2009). Alcohol selectively reduces anxiety but not fear: startle response during unpredictable vs. predictable threat. Journal of Abnormal Psychology, 118(2), 335-347. doi: 10.1037/a0015636

Moran-Santa Maria, M. M., Baker, N. L., Ramakrishnan, V., Brady, K. T., and McRae-Clark, A. (2015). Impact of acute guanfacine administration on stress and cue reactivity in cocainedependent individuals. The American Journal of Drug and Alcohol Abuse, 41(2), 146152. doi: $10.3109 / 00952990.2014 .945590$

Morgan, C., Southwick, S., Grillon, C., Davis, M., Krystal, J., and Charney, D. (1993). Yohimbine-facilitated acoustic startle reflex in humans. Psychopharmacology, 110(3), $342-6$. 
Mueller, V., Mucha, R. F., and Pauli, P. (1998). Dependence on smoking and the acoustic startle response in healthy smokers. Pharmacology Biochemistry and Behavior, 59(4), 1031-8.

Nawata, Y., Kitaichi, K., and Yamamoto, T. (2012). Increases of CRF in the amygdala are responsible for reinstatement of methamphetamine-seeking behavior induced by footshock. Pharmacology, Biochemistry, and Behavior, 101(2), 297-302. doi: 10.1016/j.pbb.2012.01.003

Nelson, B. D., Hajcak, G., and Shankman, S. A. (2015). Event-related potentials to acoustic startle probes during the anticipation of predictable and unpredictable threat. Psychophysiology, 52(7), 887-894. doi: 10.1111/psyp.12418

Newman, S., and Goldman, H. (2008). Putting Housing First, Making Housing Last: Housing Policy for Persons With Severe Mental Illness. American Journal of Psychiatry, 165(10), 1242-1248. doi: 10.1176/appi.ajp.2008.08020279

O’Dell, L. E., Roberts, A. J., Smith, R. T., and Koob, G. F. (2004). Enhanced alcohol selfadministration after intermittent versus continuous alcohol vapor exposure. Alcoholism, Clinical and Experimental Research, 28(11), 1676-1682.

Olive, M. F., Koenig, H. N., Nannini, M. A., and Hodge, C. W. (2002). Elevated extracellular CRF levels in the bed nucleus of the stria terminalis during ethanol withdrawal and reduction by subsequent ethanol intake. Pharmacology, Biochemistry and Behavior, $72(1-2), 213-220$.

Park, P. E., Vendruscolo, L. F., Schlosburg, J. E., Edwards, S., Schulteis, G., and Koob, G. F. (2013). Corticotropin-releasing factor (CRF) and $\alpha 2$ adrenergic receptors mediate heroin withdrawal-potentiated startle in rats. The International Journal of Neuropsychopharmacology, 16(8), 1867-1875. doi: 10.1017/S1461145713000308 
Patrick, C. J., and Hajcak, G. (2016). RDoC: Translating promise into progress. Psychophysiology, 53(3), 415-424. doi: 10.1111/psyp.12612

Petrakis, I. L., Desai, N., Gueorguieva, R., Arias, A., O’Brien, E., Jane, J. S., Sevarino, K., et al. (2016). Prazosin for Veterans with Posttraumatic Stress Disorder and Comorbid Alcohol Dependence: A Clinical Trial. Alcoholism, Clinical and Experimental Research, 4O(1), 178-186. doi: 10.1111/acer.12926

Piasecki, T. M., Fiore, M. C., and Baker, T. B. (1998). Profiles in discouragement: two studies of variability in the time course of smoking withdrawal symptoms. Journal of Abnormal Psychology, 107(2), 238-51.

Piasecki, T. M., Niaura, R., Shadel, W. G., Abrams, D., Goldstein, M., Fiore, M. C., and Baker, T. B. (2000). Smoking withdrawal dynamics in unaided quitters. J Abnorm Psychol, 109(1), 74-86.

Piper, M. E. (2015). Withdrawal: Expanding a key addiction construct. Nicotine \& Tobacco Research, ntv048. doi: 10.1093/ntr/ntv048

Piper, M. E., Schlam, T. R., Cook, J. W., Sheffer, M. A., Smith, S. S., Loh, W.-Y., Bolt, D. M., et al. (2011). Tobacco withdrawal components and their relations with cessation success. Psychopharmacology, 216(4), 569-578. doi: 10.1007/s00213-011-2250-3

Plaza-Zabala, A., Martín-García, E., de Lecea, L., Maldonado, R., and Berrendero, F. (2010). Hypocretins regulate the anxiogenic-like effects of nicotine and induce reinstatement of nicotine-seeking behavior. The Journal of Neuroscience, 30(6), 2300-2310. doi: 10.1523/JNEUROSCI.5724-09.2010 
Rasmussen, D. D., and Kincaid, C. L. (2015). Acoustic startle in alcohol-naïve male rats predicts subsequent voluntary alcohol intake and alcohol preference. Alcohol and Alcoholism (Oxford, Oxfordshire), 50(1), 56-61. doi: 10.1093/alcalc/agu065

Robinson, O. J., Overstreet, C., Allen, P. S., Pine, D. S., and Grillon, C. (2012). Acute tryptophan depletion increases translational indices of anxiety but not fear: serotonergic modulation of the bed nucleus of the stria terminalis? Neuropsychopharmacology, 37(8), 1963-1971. doi: 10.1038/npp.2012.43

Rudoy, C. A., and Van Bockstaele, E. J. (2007). Betaxolol, a selective beta(1)-adrenergic receptor antagonist, diminishes anxiety-like behavior during early withdrawal from chronic cocaine administration in rats. Progress in Neuro-Psychopharmacology \& Biological Psychiatry, 31(5), 1119-1129. doi: 10.1016/j.pnpbp.2007.04.005

Ryabinin, A. E., Tsoory, M. M., Kozicz, T., Thiele, T. E., Neufeld-Cohen, A., Chen, A., LoweryGionta, E. G., et al. (2012). Urocortins: CRF's siblings and their potential role in anxiety, depression and alcohol drinking behavior. Alcohol, 46(4), 349-357. doi: 10/1016/j.alcohol.2011.10.007

Sakanaka, M., Shibasaki, T., and Lederis, K. (1986). Distribution and efferent projections of corticotropin-releasing factor-like immunoreactivity in the rat amygdaloid complex. Brain Research, 382(2), 213-238.

Sapolsky, R. M. (2002). Endocrinology of the stress-response. In J. B. Becker, S. M. Breedlove, D. Crews, and M. M. McCarthy (Eds.), Behavioral endocrinology (2nd ed.). (pp. 409450). MIT Press.

Sayette, M. A. (1993). An appraisal-disruption model of alcohol's effects on stress responses in social drinkers. Psychological Bulletin, 114(3), 459-476. 
Schank, J., Ryabinin, A., Giardino, W., Ciccocioppo, R., and Heilig, M. (2012). Stress-related neuropeptides and addictive behaviors: beyond the usual suspects. Neuron, 76(1), 192208. doi: 10.1016/j.neuron.2012.09.026

Schmitz, A., and Grillon, C. (2012). Assessing fear and anxiety in humans using the threat of predictable and unpredictable aversive events (the NPU-threat test). Nature Protocols, 7(3), 527-532. doi: 10.1038/nprot.2012.001

Schroder, K. E., and Perrine, M. W. (2007). Covariations of emotional states and alcohol consumption: Evidence from 2 years of daily data collection. Social Science \& Medicine, $5,2588-2602$.

Schulkin, J., Morgan, M. A., and Rosen, J. B. (2005). A neuroendocrine mechanism for sustaining fear. Trends in Neurosciences, 28(12), 629-635. doi:

10.1016/j.tins.2005.09.009

Schwandt, M. L., Cortes, C. R., Kwako, L. E., George, D. T., Momenan, R., Sinha, R., Grigoriadis, D. E., et al. (2016). The CRF1 antagonist verucerfont in anxious alcohol dependent women: Translation of neuroendocrine, but not of anti-craving effects. Neuropsychopharmacology. doi: 10.1038/npp.2016.61

Shackman, A. J., and Fox, A. S. (2016). Contributions of the central extended amygdala to fear and anxiety. The Journal of Neuroscience, 36(31), 8050-8063. doi:

\subsection{3/JNEUROSCI.0982-16.2016}

Shaham, Y., Erb, S., Leung, S., Buczek, Y., and Stewart, J. (1998). CP-154,526, a selective, nonpeptide antagonist of the corticotropin-releasing factor 1 receptor attenuates stressinduced relapse to drug seeking in cocaine- and heroin-trained rats. Psychopharmacology, 137(2), 184-190. 
Shaham, Y., Erb, S., and Stewart, J. (2000). Stress-induced relapse to heroin and cocaine seeking in rats: a review. Brain research Brain research reviews, 33(1), 13-33.

Shaham, Y., Funk, D., Erb, S., Brown, T. J., Walker, C., and Stewart, J. (1997). Corticotropinreleasing factor, but not corticosterone, is involved in stress-induced relapse to heroinseeking in rats. The Journal of Neuroscience, 17(7), 2605-2614.

Shaham, Y., Highfield, D., Delfs, J., Leung, S., and Stewart, J. (2000). Clonidine blocks stressinduced reinstatement of heroin seeking in rats: an effect independent of locus coeruleus noradrenergic neurons. European Journal of Neuroscience, 12(1), 292-302.

Shaham, Y., and Stewart, J. (1995). Stress reinstates heroin-seeking in drug-free animals: an effect mimicking heroin, not withdrawal. Psychopharmacology, 119(3), 334-341.

Shaham, Y., and de Wit, H. (2016). Lost in Translation: CRF1 Receptor Antagonists and Addiction Treatment. Neuropsychopharmacology, 41(12), 2795-2797. doi: 10.1038/npp.2016.94

Shankman, S. A., Nelson, B. D., Sarapas, C., Robison-Andrew, E. J., Campbell, M. L., Altman, S. E., McGowan, S. K., et al. (2013). A psychophysiological investigation of threat and reward sensitivity in individuals with panic disorder and/or major depressive disorder. Journal of abnormal psychology, 122(2), 322-338. doi: 10.1037/a0030747

Shepard, J. D., Bossert, J. M., Liu, S. Y., and Shaham, Y. (2004). The anxiogenic drug yohimbine reinstates methamphetamine seeking in a rat model of drug relapse. Biological psychiatry, 55(11), 1082-1089. doi: 10.1016/j.biopsych.2004.02.032

Sher, K. J. (1987). Stress response dampening. In H. T. Blane and K. E. Leonard (Eds.), Psychological Theories of Drinking and Alcoholism (pp. 227-271). New York: Guilford Press. 
Shiffman, S., and Waters, A. J. (2004). Negative affect and smoking lapses: a prospective analysis. Journal of Consulting and Clinical Psychology, 72(2), 192-201. doi: 10.1037/0022-006X.72.2.192

Silberman, Y., and Winder, D. G. (2013). Emerging role for corticotropin releasing factor signaling in the bed nucleus of the stria terminalis at the intersection of stress and reward. Frontiers in Addictive Disorders and Behavioral Dyscontrol, 4, 42. doi: 10.3389/fpsyt.2013.00042

Simpson, T. L., Malte, C. A., Dietel, B., Tell, D., Pocock, I., Lyons, R., Varon, D., et al. (2015). A pilot trial of prazosin, an alpha-1 adrenergic antagonist, for comorbid alcohol dependence and posttraumatic stress disorder. Alcoholism, Clinical and Experimental Research, 39(5), 808-817. doi: 10.1111/acer.12703

Simpson, T. L., Saxon, A., Meredith, C., Malte, C., Mcbride, B., Ferguson, L., Gross, C., et al. (2009). A pilot trial of the alpha-1 adrenergic antagonist, prazosin, for alcohol dependence. Alcoholism: Clinical and Experimental Research, 33(2), 255-263. doi: 10.1111/j.1530-0277.2008.00807.x

Sinha, R. (2008). Chronic stress, drug use, and vulnerability to addiction. Annals of the New York Academy of Sciences, 1141, 105-130. doi: 10.1196/annals.1441.030

Sinha, R. (2009). Modeling stress and drug craving in the laboratory: implications for addiction treatment development. Addiction biology, 14(1), 84-98. doi: 10.1111/j.13691600.2008.00134.x

Sinha, R., Fox, H. C., Hong, K.-I. A., Hansen, J., Tuit, K., and Kreek, M. J. (2011). Effects of adrenal sensitivity, stress- and cue-induced craving, and anxiety on subsequent alcohol 
relapse and treatment outcomes. Archives of General Psychiatry, 68(9), 942-952. doi: 10.1001/archgenpsychiatry.2011.49

Sinha, R., Garcia, M., Paliwal, P., Kreek, M. J., and Rounsaville, B. J. (2006). Stress-induced cocaine craving and hypothalamic-pituitary-adrenal responses are predictive of cocaine relapse outcomes. Archives of General Psychiatry, 63(3), 324-331. doi:

10.1001/archpsyc.63.3.324

Sinha, R., Kimmerling, A., Doebrick, C., and Kosten, T. (2007). Effects of lofexidine on stressinduced and cue-induced opioid craving and opioid abstinence rates: preliminary findings. Psychopharmacology, 190(4), 569-574. doi: 10.1007/s00213-006-0640-8

Sinha, R., Shaham, Y., and Heilig, M. (2011). Translational and reverse translational research on the role of stress in drug craving and relapse. Psychopharmacology, 218(1), 69-82. doi: $10.1007 / \mathrm{s} 00213-011-2263-\mathrm{y}$

Skelton, K. H., Gutman, D. A., Thrivikraman, K. V., Nemeroff, C. B., and Owens, M. J. (2007). The CRF1 receptor antagonist R121919 attenuates the neuroendocrine and behavioral effects of precipitated lorazepam withdrawal. Psychopharmacology, 192(3), 385-396. doi: 10.1007/s00213-007-0713-3

Smith, R., and Aston-Jones, G. (2008). Noradrenergic transmission in the extended amygdala: role in increased drug-seeking and relapse during protracted drug abstinence. Brain structure \& function, 213(1-2), 43-61. doi: 10.1007/s00429-008-0191-3

Solomon, R. L., and Corbit, J. D. (1973). An opponent-process theory of motivation: II. Cigarette addiction. Journal of Abnormal Psychology, 81(2), 158-171. doi: $10.1037 / \mathrm{h} 0034534$ 
Solomon, R. L., and Corbit, J. D. (1974). An opponent-process theory of motivation: I. Temporal dynamics of affect. Psychological Review, 81(2), 119-145.

Somerville, L. H., Whalen, P. J., and Kelley, W. M. (2010). Human bed nucleus of the stria terminalis indexes hypervigilant threat monitoring. Biological Psychiatry, 68, 416-424. doi: 10/1016/j.biopsych.2010.04/002

Steele, C. M., and Josephs, R. A. (1990). Alcohol myopia. Its prized and dangerous effects. American psychologist, 45(8), 921-33.

Stine, S., Grillon, C., Morgan III, C. A., Kosten, T., Charney, D., and Krystal, J. H. (2001). Methadone patients exhibit increased startle and cortisol response after intravenous yohimbine. Psychopharmacology, 154(3), 274-281. doi: 10.1007/s002130000644

Stine, S., Southwick, S., Petrakis, I., Kosten, T., Charney, D., and Krystal, J. (2002). Yohimbineinduced withdrawal and anxiety symptoms in opioid-dependent patients. Biological psychiatry, 51(8), 642-51.

Swerdlow, N. R., Geyer, M. A., Vale, W. W., and Koob, G. F. (1986). Corticotropin-releasing factor potentiates acoustic startle in rats: Blockade by chlordiazepoxide. Psychopharmacology, 88, 142-152.

Tiffany, S. T. (1990). A cognitive model of drug urges and drug-use behavior: Role of automatic and nonautomatic processes. Psychological Review, 97(2), 147-168.

Verplaetse, T. L., Weinberger, A. H., Smith, P. H., Cosgrove, K. P., Mineur, Y. S., Picciotto, M. R., Mazure, C. M., et al. (2015). Targeting the noradrenergic system for gender-sensitive medication development for tobacco dependence. Nicotine \& Tobacco Research, 17(4), 486-495. doi: 10.1093/ntr/ntu280 
Walker, D., and Davis, M. (1997a). Anxiogenic Effects of High Illumination Levels Assessed with the Acoustic Startle Response in Rats. Society of Biological Psychiatry, 42, 461471.

Walker, D., and Davis, M. (1997b). Double dissociation between the involvement of the bed nucleus of the stria terminalis and the central nucleus of the amygdala in startle increases produced by conditioned versus unconditioned fear. The Journal of Neuroscience, 17(23), 9375-9383.

Walker, D., and Davis, M. (2002). Light-enhanced startle: further pharmacological and behavioral characterization. Psychopharmacology, 159(3), 304-310. doi: $10.1007 / \mathrm{s} 002130100913$

Walker, D., and Davis, M. (2008). Role of the extended amygdala in short-duration versus sustained fear: A tribute to Dr. Lennart Heimer. Brain Structure and Function, 213(1-2), 29-42. doi: 10.1007/s00429-008-0183-3

Walker, D., Toufexis, D. J., and Davis, M. (2003). Role of the bed nucleus of the stria terminalis versus the amygdala in fear, stress, and anxiety. European Journal of Pharmacology, $463,199-216$.

Walker, D., Yang, Y., Ratti, E., Corsi, M., Trist, D., and Davis, M. (2009). Differential effects of the CRF-R1 antagonist GSK876008 on fear-potentiated, light- and CRF-enhanced startle suggest preferential involvement in sustained vs phasic threat responses. Neuropsychopharmacology, 34(6), 1533-1542. doi: 10.1038/npp.2008.210

Weinshenker, D., and Schroeder, J. (2007). There and back again: A tale of norepinephrine and drug addiction. Neuropsychopharmacology, 32(7), 1433-1451. doi: 10.1038/sj.npp.1301263 
Witkiewitz, K. (2011). Predictors of heavy drinking during and following treatment. Psychology of Addictive Behaviors, 25(3), 426-438. doi: 10.1037/a0022889

Zislis, G., Desai, T., Prado, M., Shah, H., and Bruijnzeel, A. (2007). Effects of the CRF receptor antagonist D-Phe CRF(12-41) and the alpha2-adrenergic receptor agonist clonidine on stress-induced reinstatement of nicotine-seeking behavior in rats. Neuropharmacology, 53(8), 958-66. doi: 10.1016/j.neuropharm.2007.09.007

Zorrilla, E. P., and Koob, G. F. (2010). Progress in corticotropin-releasing factor-1 antagonist development. Drug Discovery Today, 15(9-10), 371-383. doi:

10.1016/j.drudis.2010.02.011 


\section{Figure Captions}

\section{Figure 1. The elicitation and measurement of startle potentiation in rodents and humans.}

Figure 1 illustrates methods for the elicitation and measurement of startle potentiation during cued threat in rodents and humans. In this paper, we review evidence that the psychological and neural mechanisms for startle potentiation are comparable across species. This evidence combines with the highly parallel methods in rodents and humans to position startle potentiation during cued threat for effective translational and reverse translational research across species. Cue (left column): Across species, cued threat is established by pairing electric shock (depicted as red lightning bolt) with a brief presentation of a distinct cue (Cue+; e.g., colored geometric shape on computer monitor in humans, light turned on in rodents). This Cue+ condition is typically contrasted with a no-threat condition (Cue-; e.g., alternative geometric shape in humans, light off in rodents).

Measurement (center column): During each cue condition, the startle response is elicited across species by a sudden, intense, acoustic noise (i.e., the "startle probe" depicted by speaker image). In rodents, startle response magnitude is measured by quantifying cage movement (via accelerometer) caused by the reflexive movement of their full body to the startle probe. In humans, startle response magnitude is measured by quantifying their reflexive eye blink (via electromyography recording from the orbicularis oculi muscle under the eye) to the startle probe. Potentiation (right column): Across species, startle potentiation represents a contrast of startle response magnitude in the Cue+ vs. Cue- conditions.

Figure (C) Chris Kubiak, Drawski LLC.

Figure 2. No-Shock, Predictable Shock, Unpredictable Shock (NPU) task. 
In the NPU task, participants view a series of distinct visual cues presented briefly (e.g., $5 \mathrm{~s}$ ) on a computer monitor. Cues are presented in a counterbalanced blocked design in three different conditions: No Shock, Predictable Shock, and Unpredictable Shock. The upper panel depicts an exemplar of one within-subject counterbalanced order of blocks. The lower panel displays examples of each condition. Across all conditions, cues are presented sequentially and separated by variable inter-trial intervals (ITI). In No Shock, participants are instructed that no electric shocks will be administered at any time. In Predictable Shock, participants are instructed that shocks will be administered only at the end of cues and that no shocks will ever be administered during ITIs. In Unpredictable Shock, participants are instructed that shocks can be administered at any time, both during cues and ITIs. The startle response is elicited with "startle probes" (50 ms acoustic white noise). Startle potentiation is calculated separately in Predictable and Unpredictable Shock conditions relative to No Shock and serves as the primary dependent measure of defensive reactivity to these shock threat stressors. A figure legend is provided in the left panel.

Several variations of the NPU task have been used across laboratories that vary most notably on the number of cues per block, the cue-shock contingency in Predictable Shock (i.e., All vs. subset of predictable shock cues are shocked), and the placement of shock in Unpredictable Shock (i.e., during cues and ITI vs. only ITI). Figure modified with permission from Schmitz \& Grillon (2012).

\section{Figure 3. Alcohol effect sizes for startle potentiation to predictable and unpredictable} shock. 
This forest plot depicts the size of the effect of alcohol administration on startle potentiation to predictable and unpredictable shock across five independent studies. These five studies tested the effect of a single administration of alcohol on distinct manipulations of unpredictability based on the timing and probability combined (i.e., the NPU task; Moberg \& Curtin, 2009; N = 64), timing alone (Hefner, Moberg, Hachiya, \& Curtin, 2013; N =68), probability (Hefner \& Curtin, 2012; $\mathrm{N}=120$ ), intensity (Bradford, Shapiro, \& Curtin, 2013; N = 89), and location (Bradford, Starr, Motschman, \& Curtin, in prep; $\mathrm{N}=94$ ) of the shock threat. Study effect sizes depict the difference in startle potentiation (in $\mu \mathrm{V}$ ) between intoxicated (target $\mathrm{BAC}=0.08 \%$ ) and sober participants. The figure also includes the variance weighted, mean effect sizes across studies for alcohol on startle potentiation to unpredictable and predictable shock and on the difference between unpredictable and predictable shock (i.e., the Alcohol X Threat Type interaction). Error bars depict $95 \%$ confidence intervals surrounding each effect size. Confidence intervals that do not overlap 0 indicate significant effects of alcohol.

Alcohol produced significantly greater reduction in startle potentiation to unpredictable than predictable shock in every study. The mean size of alcohol's effect across studies was approximately 3-fold greater for unpredictable than predictable shock.

Figure (C) Jesse Kaye, Daniel Bradford, Kate Magruder, \& John Curtin. 
Kaye 62

Figure 1
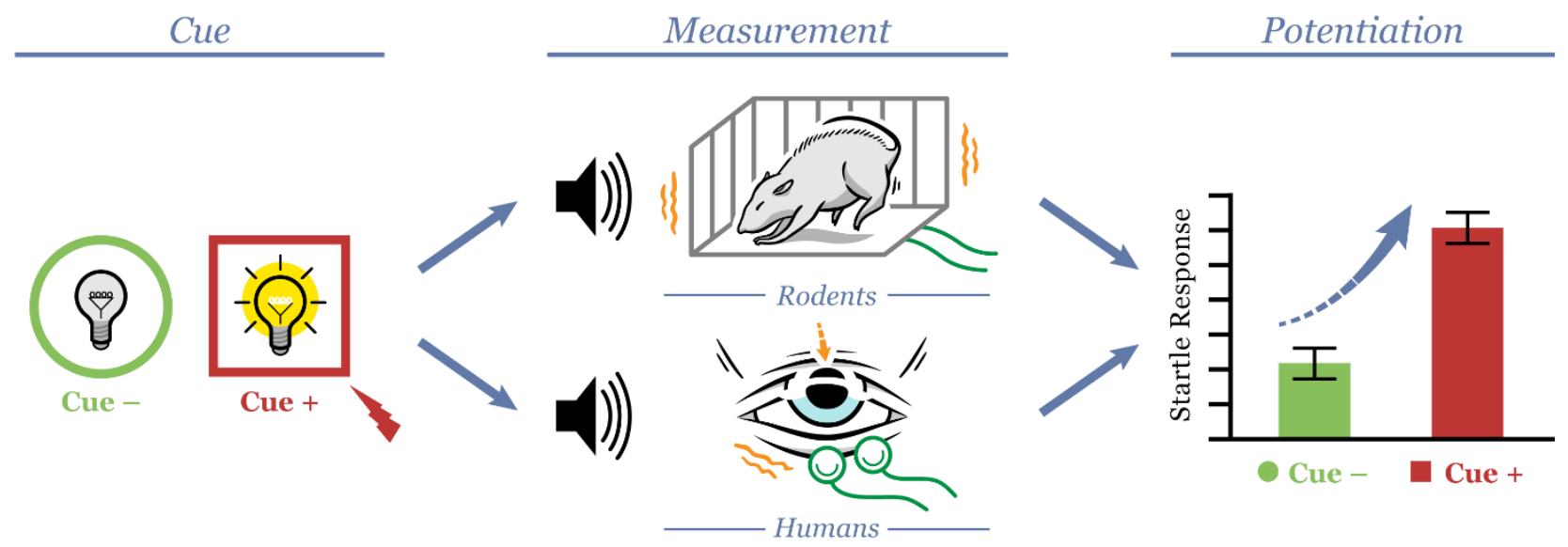
Figure 2
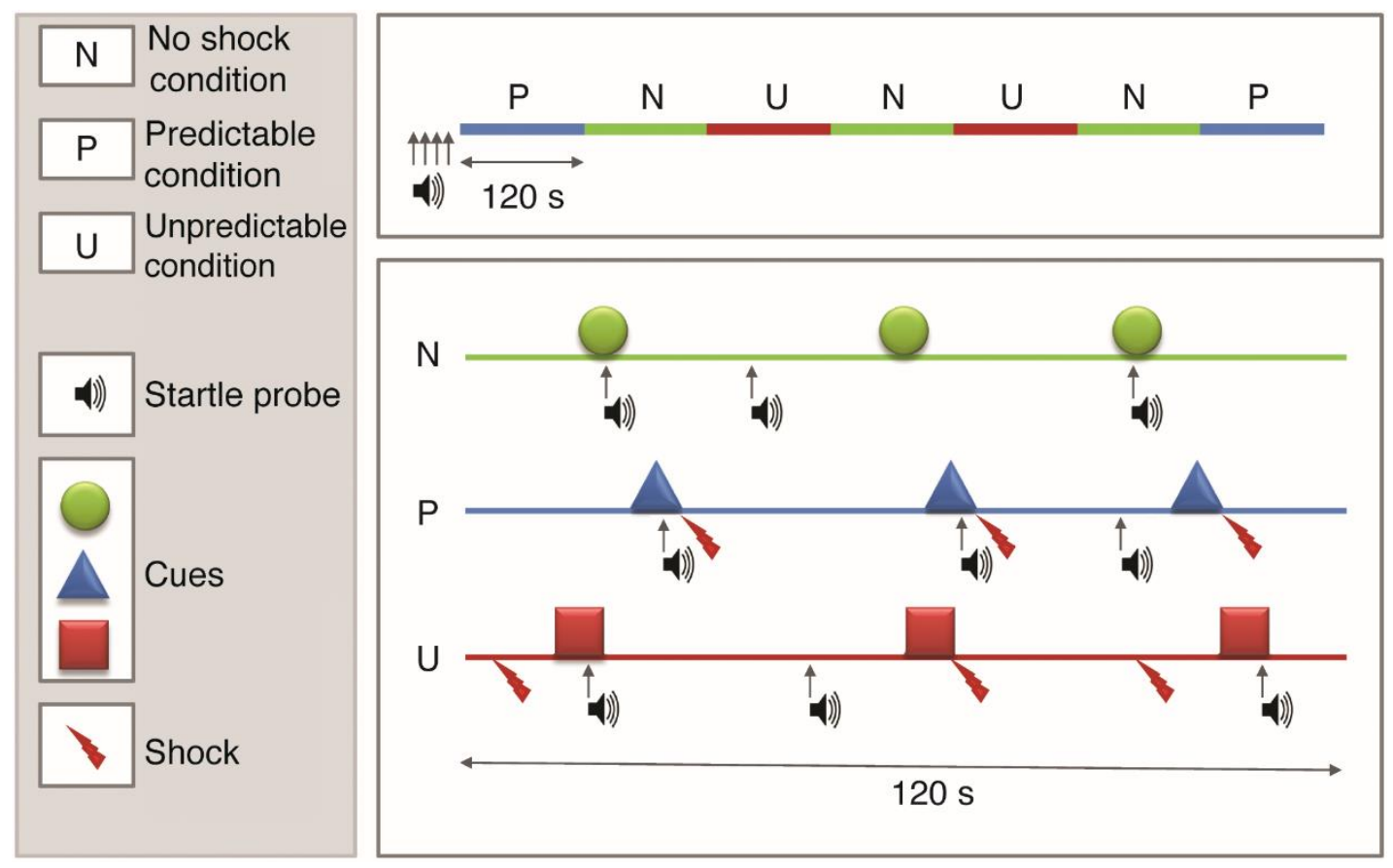


\section{Figure 3}

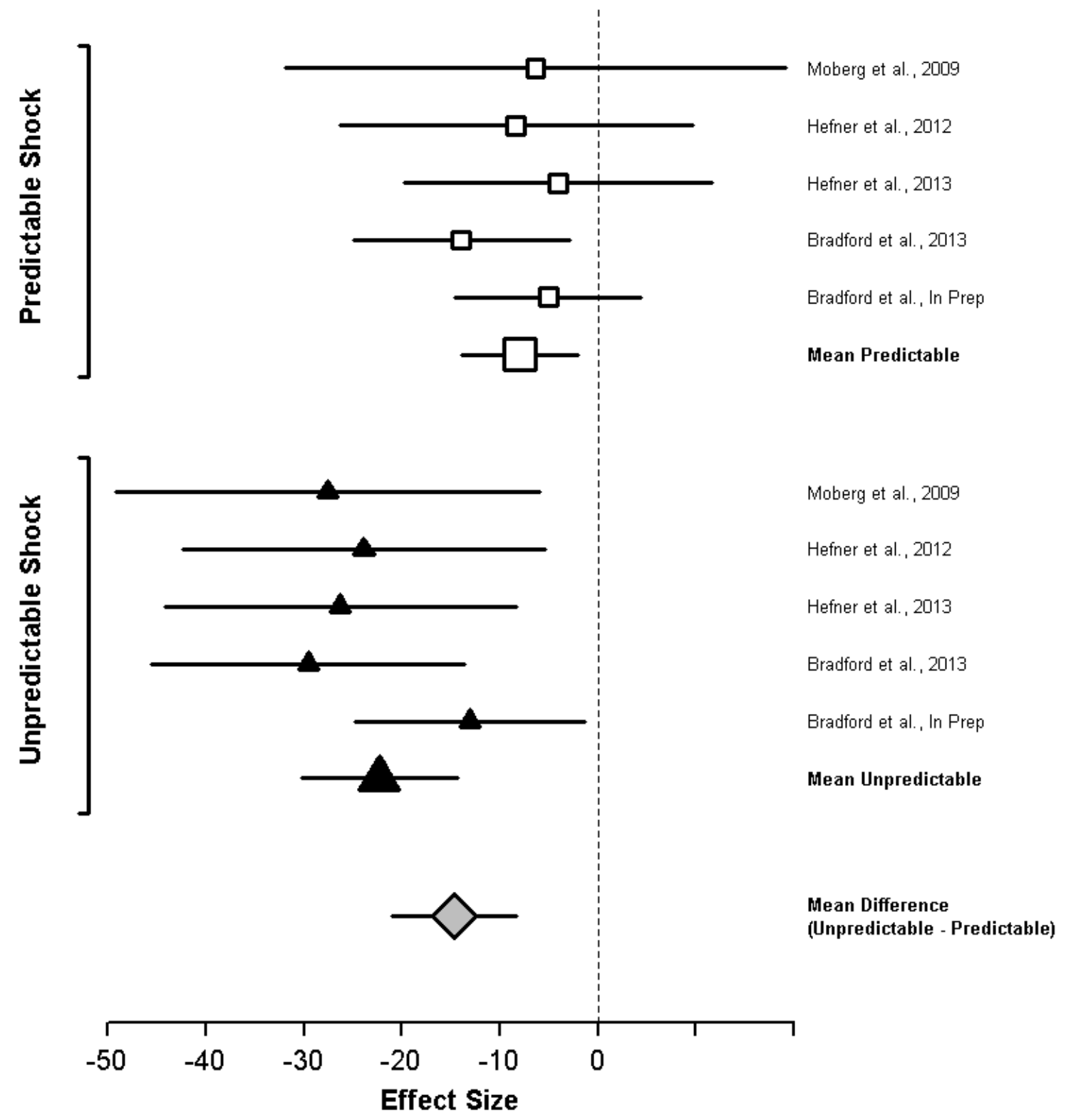




\section{Endnotes}

${ }^{1}$ For the remainder of this review, we use the term "drugs" to include alcohol and nicotine. We focus on putatively common effects across drugs on affective, behavioral, and other response to stressors (Baker et al., 2004; Koob and Le Moal, 2008a). Of course, we recognize that the precise mechanisms through which different drugs impact response to stressors may differ and that these drugs also have unique effects on other stressor-independent mechanisms (e.g., Badiani et al., 2011).

${ }^{2}$ Koob and colleagues have articulated distinct mechanisms involving between-system and within-system neuroadaptations that act in concert to maintain affective homeostasis in the face of chronic drug use (e.g., see Koob and Le Moal, 2008a, pp. 35-38). We focus primarily on a between-system adaptation where brain stress systems are recruited and adapt to oppose druginduced positive affect and reward system activation. Later, we briefly discuss a potentially novel within-system adaptation of the stress system suggested by emerging research with unpredictable startle potentiation in humans.

${ }^{3}$ We focus on CRF and NE neurotransmitter systems because they have received the most empirical support to date regarding their role in stress neuroadaptations in addiction. These neurotransmitter families have complex receptor structure and endogenous ligands. For example, $\mathrm{CRF}$ and urocortins both bind to CRF receptors. There are major classes of receptor subtypes for both CRF (e.g., $\mathrm{CRF}_{1}, \mathrm{CRF}_{2}$ ) and $\mathrm{NE}$ (e.g., $\alpha 1, \alpha 2, \beta$ ), including further subdivisions within each class (e.g., $\left.\alpha 2_{\mathrm{A}-\mathrm{C}}\right)$. These receptor families have different anatomical distributions, receptor affinity, and synaptic locations, all of which have important influences on their function (for comprehensive reviews see Bale and Vale, 2004; Weinshenker and Schroeder, 2007; Zorrilla and Koob, 2010). It is beyond the scope and goals of this paper to review the literature at this level of anatomical detail. Instead, we direct readers to authoritative reviews that provide further nuance as appropriate throughout the paper.

There are also an increasing number of other neurotransmitter systems that appear to manifest stress neuroadaptations including urocortin, dynorphin, neuropeptide $\mathrm{Y}$, hypocretins/orexin, GABA, and many more. For reviews of the role of these systems in stress-relevant processes in addiction see (Koob, 2013; Mahler et al., 2012; Ryabinin et al., 2012; Schank et al., 2012).

${ }^{4} \mathrm{CRF}$ receptors were broadly implicated in these effects initially using non-selective CRF receptor antagonists, but accumulating evidence suggests that $\mathrm{CRF}_{1}$ receptors may be the more critical target for treating stress-induced relapse (Heilig et al., 2011; but see Giardino and Ryabinin, 2012; Heilig, 2012). Conversely, all three major families of NE receptors have been implicated in stress-induced relapse processes. Therefore, for simplicity we refer broadly to "NE antagonists" to include drugs that effectively reduce NE activity either via post-synaptic $\alpha 1$ and $\beta$ antagonists (e.g., prazosin, propranolol) or pre-synaptic $\alpha 2$ autoreceptor agonists (e.g., clonidine; for review see Mantsch et al., 2016; Smith and Aston-Jones, 2008).

${ }^{5}$ Yohimbine administration has been used as one common method to manipulate stress-relevant NE neurotransmission via NE alpha-2 antagonism in both rodent models and humans. However, recent research has suggested that yohimbine's effect on operant responding in drug 
reinstatement animal models may be mediated partially by distinct non-stress and/or non-NE mechanisms (Brown et al., 2009; Chen et al., 2015; see also, Mantsch et al., 2016). Future research is needed to clarify the pharmacological, motivational, and behavioral mechanisms involved in yohimbine-induced reinstatement of drug-seeking (España et al., 2016).

${ }^{6}$ HPA axis function is regulated by a classic negative feedback loop, where glucocorticoids inhibit further release of CRF from the hypothalamus to provide safeguard against adverse effects from excessive exposure to glucocorticoids. However, glucocorticoids also simultaneously stimulate CRF activity in the extended amygdala. These observations raise the intriguing possibility that HPA axis adaptations following chronic drug use may both protect the periphery (via negative feedback) but also facilitate extrahypothalamic CRF stress neuroadaptations (via feedforward mechanisms; Koob, 2015; Schulkin et al., 2005).

${ }^{7}$ The more recent experiments in this program of research have used additional dependent measures beyond startle potentiation to demonstrate convergent validity and begin to examine cognitive correlates of alcohol's effects on reactivity to unpredictable stressors. Bradford et al (2013, in prep) both observed comparable selective effects of alcohol on unpredictable stressors across self-reported fear/anxiety and startle potentiation. Bradford et al (in prep) demonstrated that alcohol administration also selective reduces emotionally motivated attention associated with unpredictable stressors measured with the probe P3 component of the event-related potential. More broadly, these experiments demonstrate the flexibility of these cued threat tasks to incorporate multiple dependent measures across domains of analysis. 